Review

\title{
Cyclodextrins as encapsulation agents for plant bioactive compounds
}

\author{
Eva Pinho ${ }^{\mathrm{a}, \mathrm{b}, \mathrm{c}, *}$, Martin Grootveld ${ }^{\mathrm{b}}$, Graça Soares ${ }^{\mathrm{c}}$, Mariana Henriques ${ }^{\mathrm{a}}$ \\ a Institute of Biotechnology and Bioengineering, University of Minho, Campus Gualtar, 4710-057 Braga, Portugal \\ ${ }^{\mathrm{b}}$ Leicester School of Pharmacy, Faculty of Health and Life Sciences, De Montfort University, The Gateway, Leicester LE1 9BH, UK \\ c Centre for Textile Science and Technology (2C2T), University of Minho, Campus Azurém, 4800-058 Guimarães, Portugal
}

\section{A R T I C L E I N F O}

\section{Article history:}

Received 27 February 2013

Received in revised form 3 August 2013

Accepted 19 August 2013

Available online $\mathrm{xxx}$

\section{Keywords:}

Cyclodextrin

Flavonoids

Inclusion complex

Pholyphenolic

Solubility

Bioavailability

\begin{abstract}
A B S T R A C T
Plants possess a wide range of molecules capable of improve healing: fibre, vitamins, phytosterols, and further sulphur-containing compounds, carotenoids, organic acid anions and polyphenolics. However, they require an adequate level of protection from the environmental conditions to prevent losing their structural integrity and bioactivity. Cyclodextrins are cyclic oligosaccharides arising from the degradation of starch, which can be a viable option as encapsulation technique. Cyclodextrins are inexpensive, friendly to humans, and also capable of improving the biological, chemical and physical properties of bioactive molecules.

Therefore, the aim of this review is to highlight the use of cyclodextrins as encapsulating agents for bioactive plant molecules in the pharmaceutical field.
\end{abstract}

(c) 2013 Elsevier Ltd. All rights reserved.

\section{Contents}

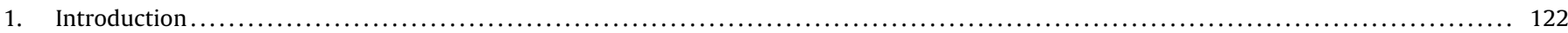

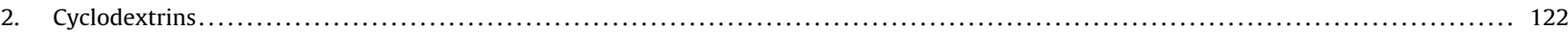

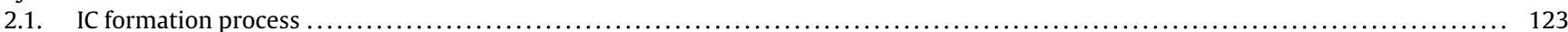

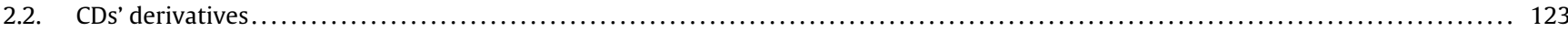

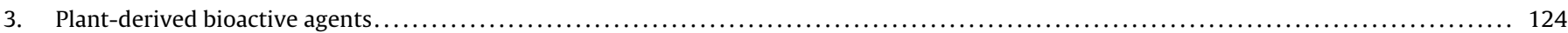

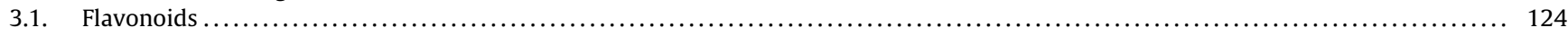

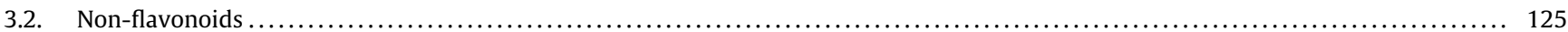

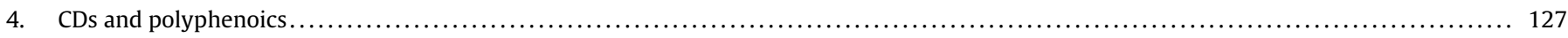

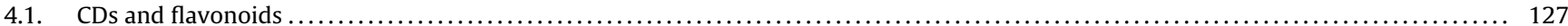

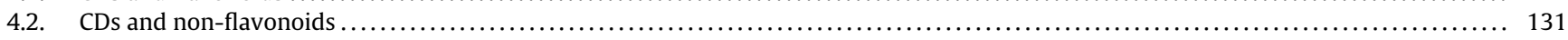

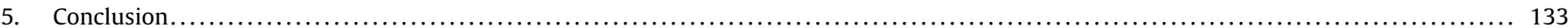

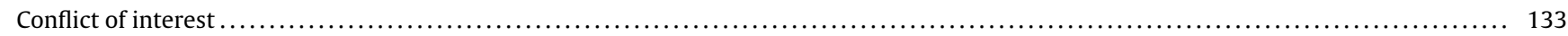

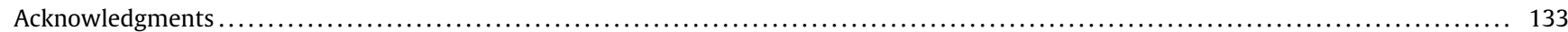

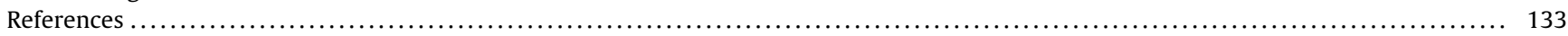

Abbreviations: CD, cyclodextrins; IC, inclusion complex; K, constant stability; UV-Vis, ultraviolet-visible light; NMR, nuclear magnetic resonance; M- $\beta$-CD, methyl- $\beta$-cyclodextrin; DM- $\beta$ CD, 2,6-dimethyl- $\beta$-CD; TM- $\beta$-CD, 2,3,6,-trimethyl- $\beta$-CD; DMA, acetylated-2,6-dimethyl- $\beta$-CD; HE- $\beta$-CD, hydroxyethyl- $\beta$-CD; HP- $\beta$-CD, 2 hydroxypropyl- $\beta-C D$; DHP, dihydroxypropyl- $\beta-C D$; G1- $\beta$-CD, glycosyl- $\beta-C D ; G 2-\beta-C D$, maltosyl- $\beta-C D$; GUG- $\beta-C D$, glucuronyl-glucosyl $-\beta-C D$; DE- $\beta-C D, 2,6-d i e t h y l-\beta-C D$; TE- $\beta$-CD, per-o-ethyl- $\beta$-CD; TA- $\beta$-CD, per-o-acetyl- $\beta$-CD; TV- $\beta$-CD, per-o-valeryl- $\beta$-CD; CME- $\beta$-CD, O-carboxymethyl-O-ethyl- $\beta$-CD; SBE- $\beta$-CD, sulfate and sulfobutylether $\beta-C D ; C M-\beta-C D$, O-carboxymethyl- $\beta$-CD; ROS, reactive oxygen species; HAT- $\beta-C D$, hydroxytrimethyl-ammoniumpropyl- $\beta$-CD; HP- $\gamma-C D, 2-h y d r o x y p r o p y l-\gamma-C D ; H P-\alpha-C D$, 2-hydroxypropyl- $\alpha-C D ; R M-\beta-C D$, randomly methylated- $\beta-C D$.

* Corresponding author at: Institute of Biotechnology and Bioengineering, University of Minho, Campus Gualtar, 4710-057 Braga, Portugal. Tel.: +351 253 604 401 ; fax: +351253604 429.

E-mail addresses: evapinho@deb.uminho.pt (E. Pinho), mgrootveld@dmu.ac.uk (M. Grootveld),gmbs@det.uminho.pt (G. Soares), mcrh@deb.uminho.pt (M. Henriques). 


\section{Introduction}

Plants are, virtually, inexhaustible sources of biologically active compounds, which are their defence mechanisms against microorganisms, insects and herbivores. Plants bioactive compounds have been; widely used by the food, cosmetic and pharmaceutical industries (Aridogan et al., 2002; Belščak-Cvitanović et al., 2011; Cowan, 1999; Gou, Zou, \& Ahn, 2011). In this field of expertise the utilisation of natural compounds instead of synthetic ones offers many advantages, such as high levels of biocompatibility, low toxicity and good availability. Plants bioactive molecules include polyphenolics, alkaloids and polysaccharides, and they all have well-documented pharmacological properties. However, polyphenolics are currently the major group of interest in view of their anti-inflammatory, antimicrobial and antioxidant properties, as well as their availability in the human diet (Aridogan et al., 2002; Belščak-Cvitanović et al., 2011; Cowan, 1999; Gou et al., 2011).

In order to have biological activity, molecules need to be capable of reaching the action site without losing integrity and be able to cross the lipophilic membrane. Plants bioactive compounds have restricted application as pharmaceutical products since they have limited water solubility, poor bioavailability, and can be easily modified by environmental factors such as temperature, $\mathrm{pH}$ and light. Therefore, in order to preserve bioactive molecules structural integrity, they need to be protected by a finishing formulation with the capacity to deliver them to the physiological targets without losing any bioactivity (Fang \& Bhandari, 2010; Munin \& EdwardsLévy, 2011).

CDs can serve as vehicles for the protection of polyphenols due to their ability to encapsulate molecules, a process involving the formation of ICs. Indeed, CDs have the capacity to modify the guest molecule's characteristics, for example, enhance the solubility of lipophilic 'guests', stabilise the 'guest' against derivatizing agents (such as oxygen, visible or ultra-violet light, and heat), control volatility and sublimation properties, allow the physical isolation of incompatible compounds (via chromatographic separation), permit taste modification by masking potentially adverse flavours, control odours and the release of such encapsulated compounds. Furthermore, CDs are now readily available, and their price and production costs have declined in recent years (Buschmann \& Schollmeyer, 2002; Del Valle, 2004; Duan, Zhao, Ossurardóttir, Thorsteinsson, \& Loftsson, 2005; Szejtli \& József, 2003; Jug, Bećirević-Laćan, \& Beæireviæ-laæan, 2008; Manakker, Vermonden, Vans Nostrum, Hennink, \& van de Manakker, 2009).

In this review, an overview of the published works on complexes between CDs and plant polyphenolics, with pharmaceutical applications, is provided. The review was based on articles published between 1996 and 2013.

\section{Cyclodextrins}

In the pharmaceutical industry, CDs are used as drug carriers to enhance the solubility, stability and bioavailability of the bioactive molecules (Uekama, Hirayama, \& Irie, 1998). They have a high level of biocompatibility and are approved by FDA (Food and Drug Administration), thus CDs are friendly to humans (Jug et al., 2008; Matsuda \& Arima, 1999; Shulman et al., 2011). CDs can complex with large group of molecules, from straight or branch aliphatic chains to polar compounds, changing their chemical, physical or biological behaviour (Arun et al., 2008).

CDs arise from starch degradation via enzymes, and are cyclic oligosaccharides with 6,7 or 8 glucose residues linked by a (1-4) glycosidic bond. In nature, they appear as $\alpha$-, $\beta$ - and $\gamma$-CDs (Fig. 1 ), although the $\beta$-form is the most commonly employed for encapsulation purposes since it is the least expensive. $C D$ molecules have a truncated cone shape, with a hydrophobic zone inside and a hydrophilic external surface (Fig. 1). Therefore, they are able to form ICs with poorly water-soluble molecules (such as polyphenolics), improving molecules' solubility (Buschmann \& Schollmeyer, 2002; Loftsson \& Duchêne, 2007; Singh, Sharma, \& Banerjee, 2002).

In addition to the solubilisation improvement, CDs protect bioactive molecules from side-effects from the environmental conditions (temperature, $\mathrm{pH}$, light) and, hence enhance their shelf-life and reduce the concentrations of the agent required to achieve a
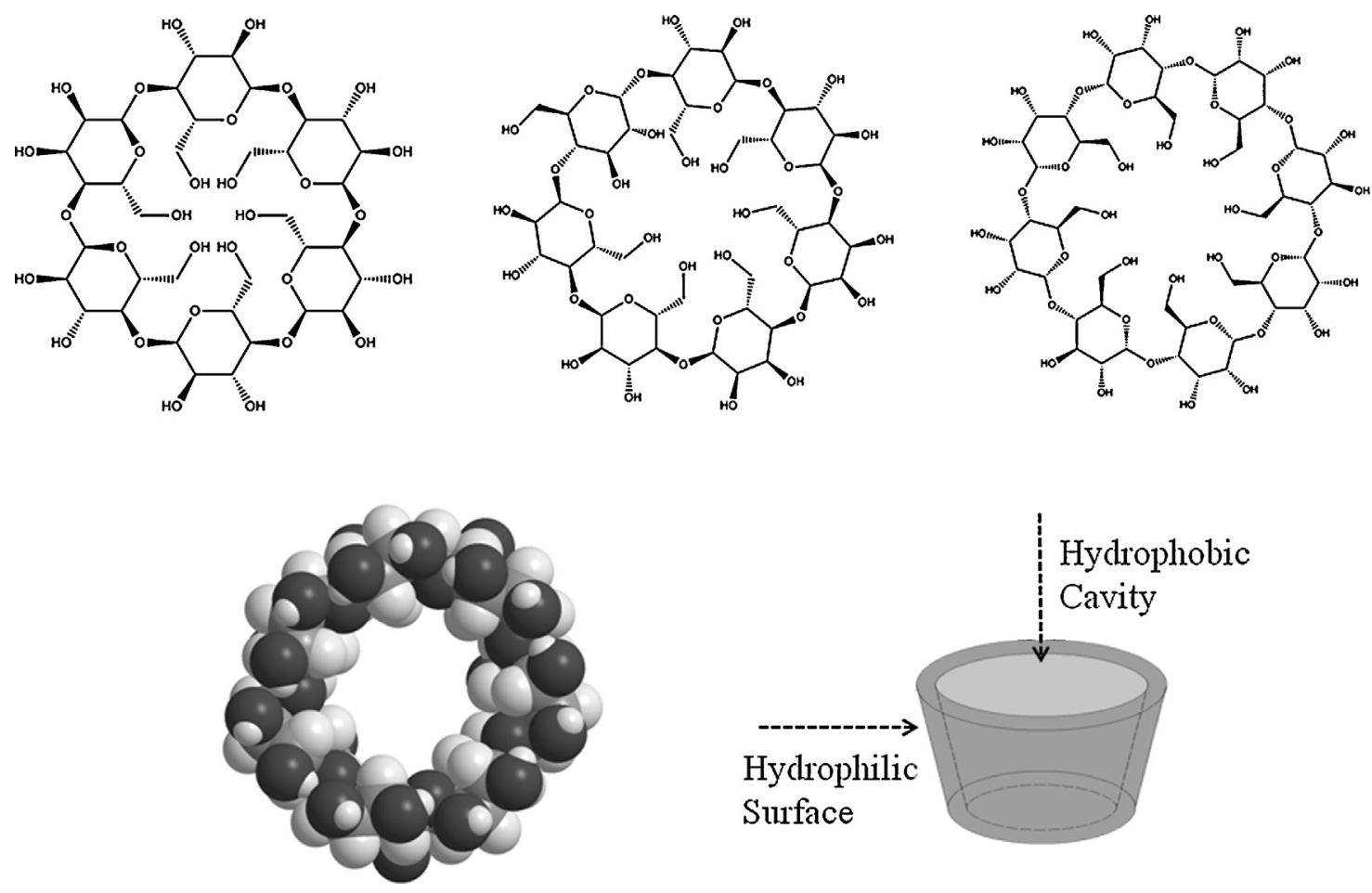

Fig. 1. Schematic representation of $\alpha-C D, \beta-C D$ and $\gamma-C D$ (left to right) and schematic representation of the $C D$ truncate aspect (Chem3D Pro 12.0 software). 


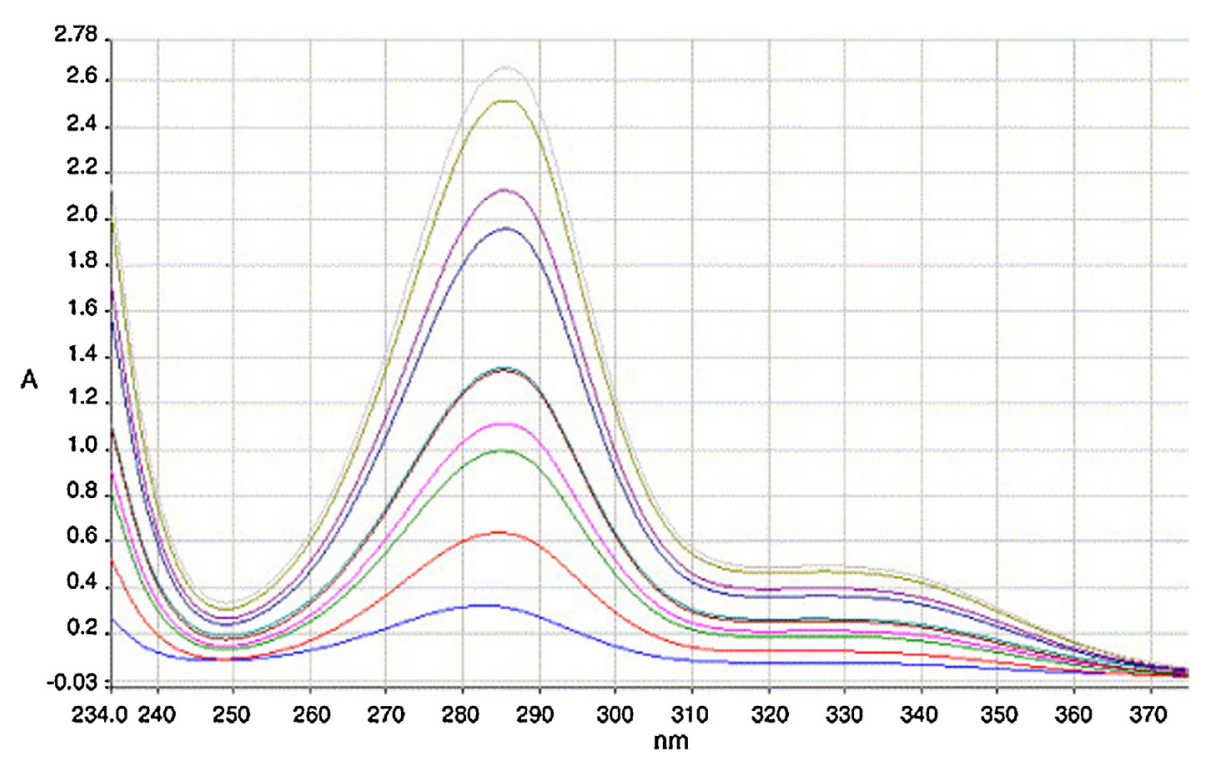

Fig. 2. UV absorption spectra of hesperidin $\left(7.2 \times 10^{-5} \mathrm{M}\right)$ in the presence of increasing concentrations of $\mathrm{HP}-\beta-\mathrm{CD}\left(0.0-9.0 \times 10^{-3} \mathrm{M}\right)(\mathrm{Tommasini}$ et al., 2005$)$.

biological effect (Carlotti, Sapino, Ugazio, \& Caron, 2010; Fang \& Bhandari, 2010).

Moreover, CDs can modify the behaviour of the encapsulated molecule, specifically by modulating the delivery rate (i.e. retarding or prolonging it), which renders the drug formulation with CDs 'non-bioequivalent' to formulations without CDs (Aqil, Munagala, Jeyabalan, \& Vadhanam, 2013; Cal \& Centkowska, 2008). Other advantage of the CDs application as carrier is CD ability to eliminate irritant or toxicological effects of the active agent, by replacing some excipients, such as $\mathrm{pH}$ regulators, solubilising agents or organic solvents (Cal \& Centkowska, 2008; Davis \& Brewster, 2004; Marques, 2010; Valenta \& Auner, 2004).

\subsection{IC formation process}

There are several methods for the formation of ICs between CDs and bioactive molecules, and the selection of the process is clearly based on the properties of the guest molecule, the facilities available and the cost involved (Marques, 2010). The most common methods are neutralisation, slurry, solution, co-precipitation, kneading, and grinding method (Hedges, 1998).

The process of inclusion of the 'guest' into the CD occurs at the supramolecular level, and hence there is a substitution of enthalpyrich water molecules from the central cavity, by the lipophilic 'guest' or moiety, and no covalent bonds are broken or formed between the IC compounds (Manakker et al., 2009; Marques, 2010). The IC is maintained via hydrophobic forces and van der Waals interactions, and also by other factors like the release of ring strain, modifications in solvent surface, tensions and also hydrogen bonds which render the IC complex more energetically stable (Del Valle, 2004; Manakker et al., 2009). IC generation represents a threedimensional fit between the CD and the 'guest' molecule, and on the specific local interactions between the CDs' surface groups and the guest molecule (Buschmann \& Schollmeyer, 2002).

The $C D$ encapsulation of the bioactive molecule induces alterations on the physicochemical characteristics of both agents. Therefore, it is possible to assess the stoichiometry of the complexes and their stability constant $(\mathrm{K})$ by analysing the modifications on the solubility, chemical reactivity and stability, UV-Vis absorbency, drug retention and permeability (Arun et al., 2008; Hirose, 2001; Marques, 2010). The stoichiometry of the IC represents the number of molecules that interact with the $C D$, in most part of the cases the $1: 1$ IC is observed; however the same CD can interact with 2 or more molecules $(1: 2)$ or one guest can complex with more than one $\mathrm{CD}(2: 1)$, not so frequent. The variable, $K$, also known as equilibrium constant or binding constant, needs to be determined by experimental methods and is a parameter that represents the thermodynamic equilibrium between the free and the complexes molecules (Szejtli \& József, 1998). Moreover, thermodynamic parameters, such as enthalpy, entropy and free Gibbs energy, must be also considered as important parameters on the evaluation of the complexation process since the temperature influences the selectivity of the binding between $\mathrm{CD}$ and the bioactive molecule (Hirose, 2001, 2007).

Therefore, in order to assess the $K$ value and the stoichiometry of the complex, evaluation of the IC concentrations and the equilibrium concentrations of the $\mathrm{CD}$ and the bioactive molecule needs to be assessed based on experimental methods. Continuous variation, slope ratio, mole ratio are some of the methods used, and the parameters are measured based on alterations on one or more physicochemical properties of the guest, for example UV-Vis absorbency spectrum (Fig. 2) or NMR (Fig. 3) (Arun et al., 2008; Hirose, 2007).

\subsection{CDs' derivatives}

In the last years, physicochemical properties and, consequently, the inclusion capacity of the natives' CD have been improved by chemical modification of their hydroxyl groups (Matsuda \& Arima, 1999). Each CDs' glucopyranose unit has 3 reactive hydroxyl groups with different ratio of reactivity and function, in the case of $\beta-C D$ it is possible to change 21 hydroxyl groups by chemical or enzymatic reaction (Szejtli \& Jozsef, 2004). The $\beta$-CD derivatives (Table 1) are, normally, distributed based in their interaction with the water molecules, i.e., hydrophilic, hydrophobic or ionisable derivatives. The first group (hydrophilic) has better solubility in water and are suitable for IC formation with poor water soluble "guest" molecules. The DM- $\beta$ CD, TM- $\beta-C D$, hydroxyalkylated CDs such as HP- $\beta-C D$ and branched CDs like $G-\beta-C D$ are some examples of hydrophilic CD derivatives. The hydrophobic derivatives, for example DE- $\beta-C D$, are capable of decrease and modulate the release rate of water soluble molecules. The ionisable CDs CM- $\beta-C D, C M E-\beta-C D$, and SBE- $\beta-C D$, can enhance the dissolution rate, the inclusion capacity and also the decrease of the side effects of some molecules (Loftsson \& Duchêne, 


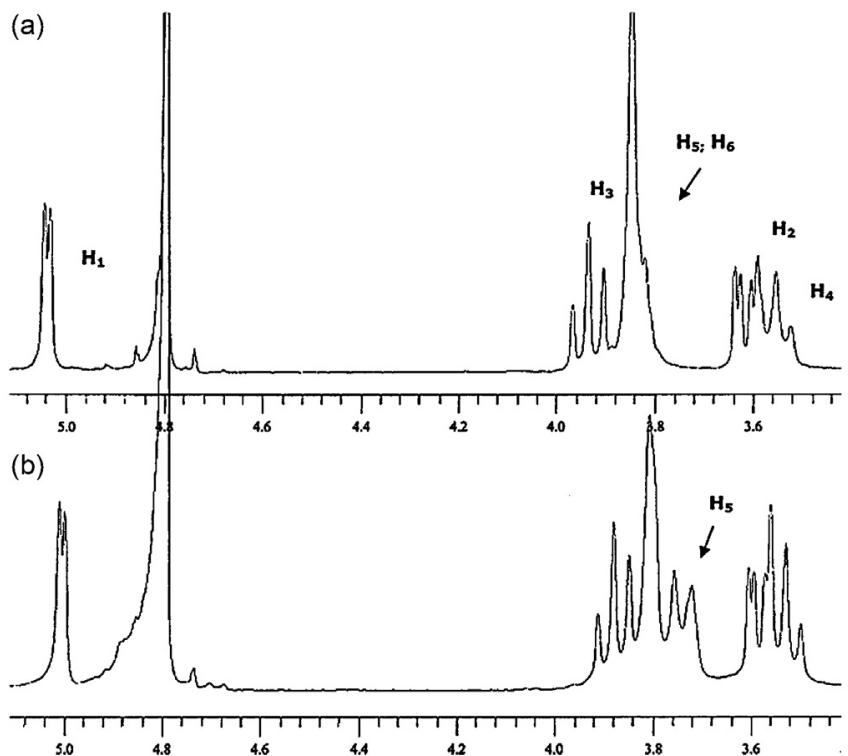

Fig. 3. NMR spectra: free $\beta-C D(a)$; inclusion complex with 3-hydroxyflavon (b). Spectra recorded in $\mathrm{D}_{2} \mathrm{O}$; signals referred to residual HDO (Calabrò et al., 2004).

Table 1

Common $\beta-C D$ derivatives.

\begin{tabular}{|c|c|}
\hline CD' derivative & Characteristic \\
\hline \multicolumn{2}{|c|}{ Hydrophilic derivatives } \\
\hline$M-\beta-C D$ & Soluble in cold water and in organic solvents \\
\hline$D M-\beta-C D$ & Surface active, hemolytic \\
\hline \multicolumn{2}{|l|}{ TM- $\beta-C D$} \\
\hline DMA- $\beta-C D$ & Soluble in water, low hemolytic \\
\hline \multicolumn{2}{|c|}{ Hydroxyalkylated- $\beta-C D$} \\
\hline $2-\mathrm{HE}-\beta-\mathrm{CD}$ & $\begin{array}{l}\text { Amorphous mixture with different degrees of } \\
\text { substitution }\end{array}$ \\
\hline $2-H P-\beta-C D$ & Highly water-soluble (_50\%), low toxicity \\
\hline \multicolumn{2}{|l|}{$3-\mathrm{HP}-\beta-\mathrm{CD}$} \\
\hline \multicolumn{2}{|l|}{$3-\mathrm{HP}-\beta-\mathrm{CD}$} \\
\hline \multicolumn{2}{|l|}{ 2,3-DHP- $\beta-C D$} \\
\hline \multicolumn{2}{|l|}{ Branched- $\beta-C D$} \\
\hline$G_{1}-\beta-C D$ & Highly water-soluble (_50\%), low toxicity \\
\hline \multicolumn{2}{|l|}{$\mathrm{G}_{2}-\beta-\mathrm{CD}$} \\
\hline \multicolumn{2}{|l|}{ GUG- $\beta-C D$} \\
\hline \multicolumn{2}{|c|}{ Hydrophobic derivatives } \\
\hline \multicolumn{2}{|l|}{ Alkylated- $\beta-C D$} \\
\hline$D E-\beta-C D$ & $\begin{array}{l}\text { Poorly water-soluble, soluble in organic solvents, } \\
\text { surface-active }\end{array}$ \\
\hline \multicolumn{2}{|r|}{ (1) } \\
\hline \multicolumn{2}{|c|}{ Acylated- $\beta-C D(C 2-C 18)$} \\
\hline TA- $\beta-C D$ & Poorly water-soluble, soluble in organic solvents \\
\hline TV- $\beta-C D$ & Film formation \\
\hline \multicolumn{2}{|c|}{ Ionaizable derivatives } \\
\hline Anionic- $\beta-C D$ & $\mathrm{p} K_{\mathrm{a}}=3-4$, soluble at $\mathrm{pH}_{-} 4$ \\
\hline CME- $\beta-C D$ & \\
\hline
\end{tabular}

2007; Matsuda \& Arima, 1999). The HP- $\beta-C D$ and the SBE- $\beta-C D$ are the most used derivatives on the pharmaceutical industry, their low toxicity and high solubility make them suitable for oral and parental application (Table 1) (Davis \& Brewster, 2004; Loftsson \& Duchêne, 2007; Stella \& Rajewski, 1997).

\section{Plant-derived bioactive agents}

Plant extracts have been used in traditional medicine, and during the past few years many studies have proved their beneficial effects on human health. The plant extract's bioactivities are commonly related with compounds like fibre, vitamins, phytosterols, sulphur-containing compounds, carotenoids, organic acid anions, together with polyphenolics (Manach et al., 2005). These kinds of molecules are plants' secondary metabolites and include a wide range of compounds, many of which are phenolics or their oxygensubstituted derivatives (Fig. 4). Polyphenolics confer protection to the plant, are responsible for plant odours (essential oils), plant pigmentation (quinines and tannins) or their flavours (e.g., terpenoid capsaicin from chilli peppers) (Cowan, 1999).

Polyphenolics are plant metabolites present in human and animal diets with a wide range of biological activities on human body, such as antioxidant, anti-inflammatory, antibacterial and antiviral (Alberto, Farías, \& Nadra, 2001; Fang \& Bhandari, 2010; Haslam \& Cai, 1994; Manach et al., 2005; Munin \& EdwardsLévy, 2011; Scalbert, Johnson, \& Saltmarsh, 2005). They share a common chemical structure: all have at least one aromatic ring, with one or more hydroxyl groups attached. The diversity of phenolic compounds present in nature results from variations in the basic chemical skeleton, such as degree of oxidation, hydroxylation, methylation, glycosylation, and conjugation with further molecules, particularly lipids, proteins, other phenolics, and biomolecular metabolites (Crozier, Jaganath, \& Clifford, 2009; Munin \& Edwards-Lévy, 2011).

Therefore, this group of natural bioactive compounds includes a range of molecules from simple, single aromatic-ring, lowmolecular-mass compounds, to large and complex tannins and polyphenolic derivatives. However, they all share two fundamental biological activities (1) radical scavenging action and (2) antioxidant properties by interaction with proteins and ions (Heim, Tagliaferro, \& Bobilya, 2002; Munin \& Edwards-Lévy, 2011; Nichols \& Katiyar, 2010; Proestos, Chorianopoulos, Nychas, \& Komaitis, 2005). This interaction is especially important if the polyphenolic is capable of complex or chelate a metal with redox-activity (for example iron or copper) (Heim et al., 2002; Munin \& EdwardsLévy, 2011; Nichols \& Katiyar, 2010; Proestos et al., 2005). The antioxidant activity of lipophilic phenolics and polyphenolics can be attributed to their action as chain-terminator for the selfperpetuating autocatalytic lipid peroxidation process, as indeed does $\alpha$-tocopherol (vitamin E).

Polyphenolics are grouped by the number and arrangement of their carbon atoms (Fig. 4) (Crozier et al., 2009). In this review, polyphenolics will be sub-divided as flavonoids and nonflavonoids.

\subsection{Flavonoids}

Flavonoids are low-molecular-mass compounds with a flavan nucleus: two aromatic rings connected by 3-carbon bridge $\left(C_{6}-C_{3}-C_{6}\right.$ ) (Heim et al., 2002; Manach et al., 2005). In plants, they are utilised in response to microbial infection. However, in animals and humans, flavonoids protect cells against damage caused by ROS, and also defend skin from damage induced by short wavelengths (Carlotti et al., 2010). Moreover, they have the capacity to inhibit the growth of a wide range of bacteria via disruption of bacterial cell walls following by their complexation with the extracellular soluble protein components (Cowan, 1999). Flavonoids also exert anti-viral actions due to their favourable oxidation potentials (Orhan, Ozçelik, Ozgen, \& Ergun, 2010; Ozçelik, Orhan, \& Toker, 2006).

The heterogeneity of the flavonoid group arises from the numerous substitutional modifications possible on the basic carbon-based skeleton. The presence of hydroxyl groups and sugars are very common, and increase their water solubility. However, methyl groups and iso-pentyl units increase their lipophilicities (Crozier et al., 2009). The bioactivities and properties of the flavonoids are critical, and are affected by small changes in the chemical structures (Cowan, 1999; Lim \& Koffas, 2010). Therefore, flavonoids can be 


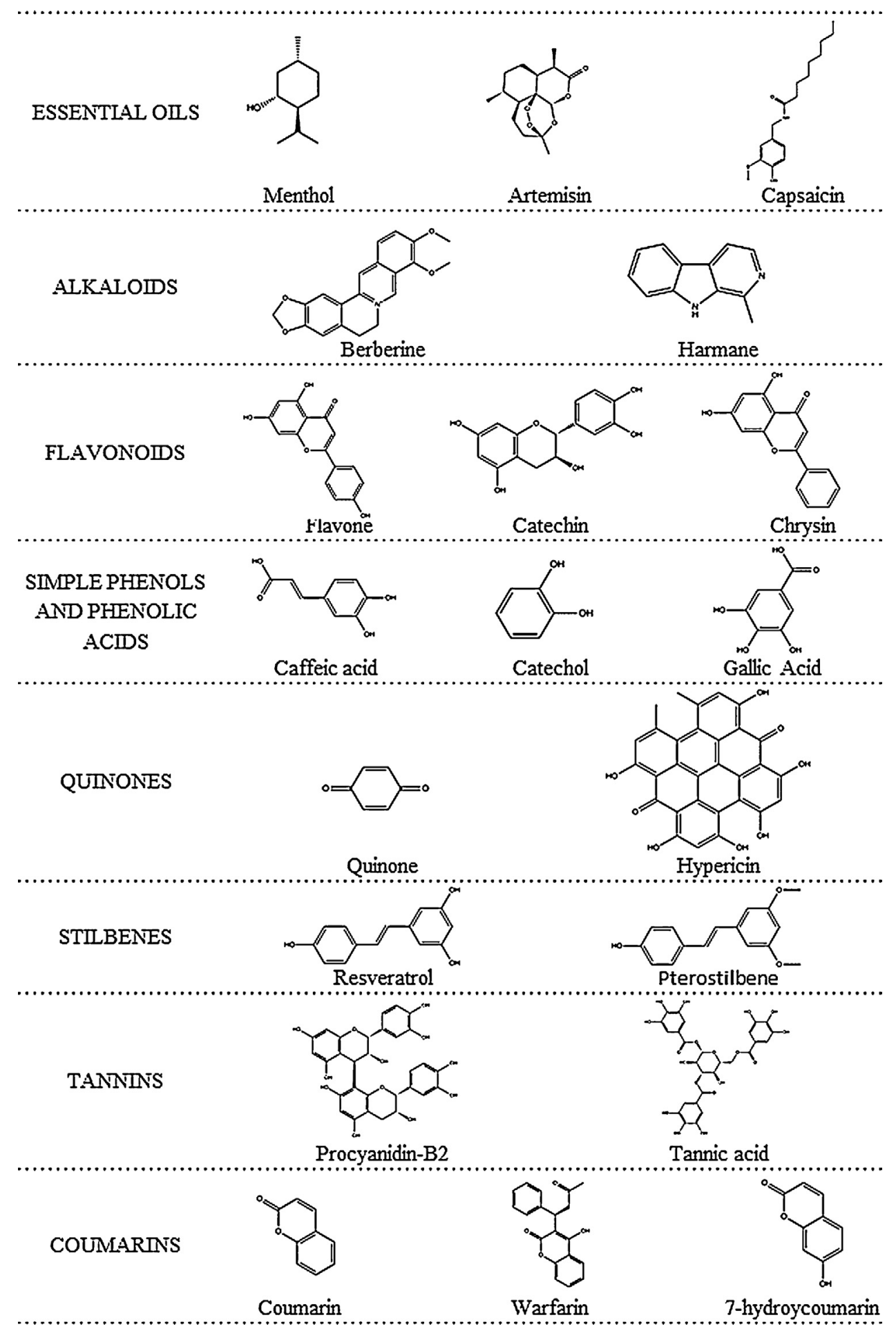

Fig. 4. Chemical structures of common plant-derivable bioactive agents (Chem3D Pro 12.0 software).

divided into sub-classes according to the precise nature of their chemical substituents, summarised in Fig. 5.

\subsection{Non-flavonoids}

Non-flavonoids include all the other polyphenolics (Fig. 4), from the simplest phenolics and phenolic acids to the phenolic complex tannin. This non-flavonoids group incorporates (1) phenolic acids, (2) quinines, (3) stilbenes, (4) tannins, and (5) coumarins.
Although phenolics and phenolic acids are single-substituted phenolic rings, they are capable of numerous biological effects. In fact, some authors have related the number of hydroxyl groups on the aromatic ring with their antimicrobial activity: the higher the number of hydroxyl groups the higher is the level of toxicity exerted to microorganisms (Crozier et al., 2009). Phenolic acids include derivatives of benzoic acids, i.e. $\left(C_{1}-C_{6}\right)$ hydroxybenzoic acids, and derivatives of cinnamic acid, i.e. $\left(\mathrm{C}_{3}-\mathrm{C}_{6}\right)$ - hydroxycinnamic acids (Dai \& Mumper, 2010; Sánchez-Maldonado, Schieber, \& Gänzle, 2011). Gallic, p-hydroxybenzoic, and ellagic acids are 


\begin{tabular}{|c|c|c|c|}
\hline Class & General Structure & Flavonoid & Substitution Pattern \\
\hline \multirow{3}{*}{ Flavan-3-ols } & & $(\dot{\div})$-catechin & $3,5,7,3^{\circ}, 4^{\prime}-\mathrm{OH}$ \\
\hline & & (-)-epicatechin & $3,5,7,3^{2}, 4^{2}-\mathrm{OH}$ \\
\hline & & Epigallocatechin gallate & $3,5,7,3^{\circ}, 4^{\prime}-\mathrm{OH}, 3$-gallate \\
\hline \multirow{6}{*}{ Flavone } & & \multirow{6}{*}{$\begin{array}{l}\text { Chrysin } \\
\text { Apigenin } \\
\text { Rutin } \\
\text { Lutiolin } \\
\text { Lutiolin glucosides }\end{array}$} & $5,7-\mathrm{OH}$ \\
\hline & & & $5,7,4^{\circ}-\mathrm{OH}$ \\
\hline & & & $5,7,3^{2}, 4^{2}-\mathrm{OH}, 3$-rutinose \\
\hline & & & $5,7,3^{\circ}, 4^{\circ}-\mathrm{OH}$ \\
\hline & & & $5,7,3^{3}-\mathrm{OH}, 4^{3}$-glucose \\
\hline & & & $5,4^{\prime}-\mathrm{OH}, 4^{\prime}, 7$-glucose \\
\hline \multirow{4}{*}{ Flavonol } & & Kaempferol & $3,5,7,4^{\prime}-\mathrm{OH}$ \\
\hline & & Quercetin & $3,5,7,3^{\circ}, 4^{\prime}-\mathrm{OH}$ \\
\hline & & Myricetin & $3,5,7,3^{\circ}, 4^{3}, 5^{3}-\mathrm{OH}$ \\
\hline & & Tamarixetin & $3,5,7,3^{\prime}-\mathrm{OH}, 4^{\prime}-\mathrm{OMe}$ \\
\hline \multirow{5}{*}{ Flavanone } & & Naringin & $5,4^{\circ}-\mathrm{OH}$-rhamnoglucose \\
\hline & & Naringenin & $5,7,4^{3}-\mathrm{OH}$ \\
\hline & & Taxifolin & $3,5,7,3^{\prime}, 4^{\prime}-\mathrm{OH}$ \\
\hline & & Eriodictyol & $5,7,3^{3}, 4^{3}-\mathrm{OH}$ \\
\hline & & Hesperidin & $5,7,3^{3}-\mathrm{OH}, 4^{2}$-OMe, 7-rutinose \\
\hline \multirow{4}{*}{ Isoflavone } & & Genistin & $5,4^{\circ}-\mathrm{OH}, 7$-glucose \\
\hline & & Genistein & $5,7,4^{\circ}-\mathrm{OH}$ \\
\hline & & Daidzin & $4^{\prime}-\mathrm{OH}, 7$-glucose \\
\hline & & Daidzein & $7,4^{\circ}-\mathrm{OH}$ \\
\hline \multirow{2}{*}{ Anthocyanin } & \multirow[t]{2}{*}{ 。 } & Apigenidin & \multirow{2}{*}{$\begin{array}{l}5,7,4^{3}-\mathrm{OH} \\
3,5,7,4^{2}-\mathrm{OH}, 3,5-\mathrm{OMe}\end{array}$} \\
\hline & & Cyanidin & \\
\hline
\end{tabular}

Fig. 5. Classification, structure and possible substitutions of the major classes of plant-derived flavonoids (Chem3D Pro 12.0 software).

representatives of the first group, and frequently occur in the form of glucosides. These compounds are water-soluble and sensitive to temperature, elevated pH values, oxidation and light (Munin \& Edwards-Lévy, 2011; Nichols \& Katiyar, 2010; Sánchez-Maldonado et al., 2011). Caffeic, ferulic and p-coumaric acids belong to the class of hydroxycinnamic acids, and are rarely found in the free form; indeed, they are usually present in nature as simple esters with hydroxy carboxylic acids or glucoses. The hydroxycinnamic acids are also sensitive to oxidation and high $\mathrm{pH}$ values, but they are poorly soluble in water (Crozier et al., 2009; Munin \& EdwardsLévy, 2011; Nichols \& Katiyar, 2010; Yang et al., 2011). Phenolic acids have been described in the literature as molecules with effective anti-microbial activity, particularly as fungicides. Their anti-microbial activity critically depends on their chemical structure, especially on the number and position of the substitution in the benzene ring, and also on the saturated chain length. The microbicidal capacity was found to be increased with augmentation of the alkyl chain length (Cueva et al., 2010; Merkl, Hradkova, Filip, \& Smidrkal, 2010; Sánchez-Maldonado et al., 2011).

Quinones are highly reactive, oxidised polyphenolic agents containing an aromatic ring (phenol group-oxidised) with two ketone substitutions. In plants, they are responsible for the brown colouration of the injured fruits, and they act as intermediates in the melanin synthesis pathway in humans. Furthermore, quinones 
exert powerful antimicrobial activities, by link irreversibly to proteins and enzymes of the surface wall and membrane of microorganisms, and thereby inactivating them. However, this mechanism of action may also be responsible for their toxicological actions in humans (Cowan, 1999).

Resveratrol serves as a typical representative of the stilbenes group. The members of this group are characterised by a $C_{6}-C_{2}-C_{6}$ structure, and are produced by plants during episodes of stress, such as those arising from disease or injury (Crozier et al., 2009; Nichols \& Katiyar, 2010; Sapino, Carlotti, Caron, Ugazio, \& Cavalli, 2008). Stilbenes, especially resveratrol, have been established as anti-ageing and antioxidant (Lim \& Koffas, 2010).

Tannins are a group of relatively high-molecular-mass biomolecules capable of tanning leather, or precipitation of gelatine from solution. Tannins based on a gallic acid precursor which the 'nucleus' can be hydrolysable as multiple esters with D-glucose, or condensed derivatives from flavonoid monomers, also known as proanthocyanidins. Tannins have the capacity to stimulate phagocytic cells, and also act as host-mediated tumour suppression or microbicidal agents. The latter activity results from the capacity of these agents to reversibly bind to proteins via hydrogen bonding and/or hydrophobic interactions (van der Waal's forces), or irreversibly via covalent bonding processes which inactivate the enzymes and adhesins present on the microbial cell wall (Cowan, 1999; Nichols \& Katiyar, 2010).

Coumarins include phenolic agents with fused benzene or $\alpha$ pyrone rings; indeed, the basic structure can provide a wide range of substitutional modifications which modulate their biological activities. The major bioactivities assigned to this group of compounds are anti-thrombotic, anti-inflammatory, anti-allergic, hepatic-protective, anti-viral, anti-carcinogenic, and vasodilator agents (Creaven et al., 2010; Grazul \& Budzisz, 2009). Warfarin, [2hydroxy-3-(3-oxo-1-phenylbutyl)chromen-4-1], serves as a good example of a coumarin-based drug available with good anticoagulant and with anti-viral properties (Cowan, 1999).

\section{CDs and polyphenoics}

The number of currently available pharmaceutical products based on polyphenolic agents is enormous, and its relevance to the global economy is consistently growing. A large number of plant extracts and their constituents, already employed in the food industry, have been adapted to serve as major active ingredients in both cosmetic and health products. However, the effectiveness of these active compounds deepens on preservation of their stability, bioactivity and bioavailability (Fang \& Bhandari, 2010). Indeed, limited water solubility, differences in the amounts of extract required for bioactive effects, and the rapid oxidation of at least some of these agents, represent some of the problems detectable during the developmental stage of drugs based on polyphenolics (Fang \& Bhandari, 2010; Marques, 2010; Munin \& Edwards-Lévy, 2011). Therefore, new approaches have been developed in order to overcome these drawbacks. Indeed, their encapsulation with $C D$ species is one of them.

A wide range of reports have been published regarding the encapsulation of natural polyphenolic agents by CDs, for food and drug delivery proposes. In this review, a brief resume of the available published work regarding the IC between the most common polyphenolics and $\mathrm{CD}$ with pharmaceutical applications will be made.

\subsection{CDs and flavonoids}

The majority of the publications in this area of expertise concern the encapsulation of flavonoids with $\beta-C D$ and its derivatives in order to improve the flavonoids water solubility and stability. The works with IC flavonoids-CDs are summarised in Table 2 and some of them are analysed with more detail.

The catechin, epicatechin and epigallocatechin-gallate are molecules representative of the flavon-3-ols subgroup. These compounds present antidiabetic and antiobesity properties, besides the antioxidant action (Haidong, Fang, Zhihong, \& Changle, 2011). Catechin isolated from grape seed was successfully complexed with $\beta$-CD with a 1:1 stoichiometry (Krishnaswamy, Orsat, \& Thangavel, 2012). Moreover, the solubility profile of epigallocatechin after encapsulation with $\beta-C D, H P-\beta-C D$ and $D M-\beta-C D$ was described by Folch-Cano, Guerrero, Speisky, Jullian, and Olea-Azar (2013). They observed that the temperature had a different influence on the $K$, dependent on the $\mathrm{CD}$ used. In the case of the native $\mathrm{CD}$, the $K$ rise with temperature increases, the opposite was observed for the $C D$ derivatives used in this study. Hence, the DM- $\beta-C D$ was the most suitable $C D$ for the complexation of epigallocatechin. The authors also described that regardless of all the IC had similar geometries, the flavonoid antioxidant rings position inside the CD cavity was different (Folch-Cano et al., 2013).

Rutin is a flavone used as capillary preservation drug with poor solubility. The encapsulation of this polyphenol with $\alpha-C D, \beta-$ $C D, H P-\beta-C D$ and DM- $\beta-C D$ was described by different authors in order to improve rutin solubility, and consequently pharmacological activity (Haiyun, Jianbin, Shuang, \& Jinhao, 2003; Shuang, Pan, Guo, Cai, \& Liu, 1997; Sri, Kondaiah, Ratna, \& Annapurna, 2007; Yu et al., 2007). For the CDs used, the IC formed was $1: 1$, this means that each molecule of cyclodextrin was capable of interacting with one molecule of rutin. Haiyun et al. (2003), Shuang et al. (1997) and Sri et al. (2007) achieved similar $K$ for the IC of rutin and $\beta-C D$ (265 and $260 \mathrm{M}^{-1}$ ). Regarding HP- $\beta-C D$, the IC formed was more stable since the constants described were higher than the ones for the rutin- $\beta-C D$. The constant value achieved by Sri and co-workers was a lower than that by Shuang and co-workers, meaning that higher temperatures $\left(28^{\circ} \mathrm{C}\right.$ in the first case) are less favourable for this IC formation. However, the DM- $\beta$-CD was the CD with higher $K$ (3217.62 $\mathrm{M}^{-1}$ ) (Yu et al., 2007) and the $\alpha$-CD with lower capacity to complex with rutin probably related to the CDs' cavity size (Shuang et al., 1997). The formation of IC improved rutin solubility and consequently its antioxidant activity and bioavailability. For instances, the complexation of rutin with $\beta$-CD improved it antioxidant protection of cells against oxidative stress (Calabrò et al., 2005). The enhancement of the oral availability by the capsulation of rutin by HP- $\beta-C D$ was proved by Miyake and co-workers after administration of the ICs to beagle dogs. The stability of rutin was improved by complexation with HP- $\beta-C D$ or HP- $\gamma-C D$, the HP groups enhanced the interactions stability of the $C D$ with rutin and the analysis of NMR showed that the rutin A ring was inside the cavity of HP- $\beta$ CD. The IC protects rutin from thermal and UV degradation (Fig. 6) and, also, increased this phenolic antioxidant capacity (Nguyen, Liu, Zhao, Thomas, \& Hook, 2013).

Chrysin is also a flavone and its pharmaceutical applications are related with its antioxidant, anti-inflammatory and antihypertension capacity. However, as most part of this kind of compounds, chrysin has low solubility in water, therefore the use of $C D$ as carrier agent improved its activity and administration (Chakraborty, Basu, Lahiri, \& Basak, 2010). Chrysin IC with $\beta-C D$ was investigated by Chakraborty et al. (2010). The complex had the stoichiometry of $1: 1$ and with a $K$ of $1005 \mathrm{M}^{-1}$, antioxidant activity of the chrysin was also improved (Chakraborty et al., 2010). Kim, Kim, \& Jung (2008) encapsulate this molecule with $H P-\beta-C D, D M-\beta-C D$, besides the native $C D$. They report the same stoichiometry $(1: 1)$ for all the $C D$ used and the HP- $\beta-C D$ had the higher $K\left(1855 \mathrm{M}^{-1}\right)$ (Kim et al., 2008). In both works, authors described that the interaction between the chrysin and the CDs occurs by the A-ring of the flavon, molecular interactions 
Table 2

Published works regarding the inclusion of polyphenolics by CDs and derivatives.

\begin{tabular}{|c|c|c|c|c|}
\hline & Polyphenolic & $\mathrm{CD}$ & Improved characteristics & References \\
\hline \multirow[t]{3}{*}{ Essential oils } & Eugenol & $\beta-C D$ & & Divakar and Maheswaran (1997) \\
\hline & Lavender & $\beta-C D$ & Solubility & Răileanu, Todan, Voicescu, Ciuculescu, and Maganu (2013) \\
\hline & Mint & $\beta-C D$ & Solubility & Răileanu et al. (2013) \\
\hline \multirow[t]{9}{*}{ Alkaloids } & Curcumin & $\alpha-C D$ & Solubility & Rahman, Cao, Steadman, Wei, and Parekh (2012) \\
\hline & & $\mathrm{HP}-\alpha-\mathrm{CD}$ & $\begin{array}{l}\text { Anti-carcinogenic } \\
\text { transdermal permeation }\end{array}$ & Ghanghoria, Kesharwani, Agashe, and Jain (2012) \\
\hline & & $\beta-C D$ & $\begin{array}{l}\text { Anti-inflammatory } \\
\text { bioavailability }\end{array}$ & Rocks et al. (2012) \\
\hline & & $H P-\beta-C D$ & Photodegradation & Mohan, Sreelakshmi, Muraleedharan, and Joseph (2012) \\
\hline & & $\mathrm{RM}-\beta-\mathrm{CD}$ & & Dhule et al. (2012) \\
\hline & & SBE- $\beta-C D$ & & Dandawate et al. (2012) \\
\hline & & HTA- $\beta-C D$ & & López-Tobar, Blanch, Ruiz del Castillo, and Sanchez-Cortes (2012) \\
\hline & & $\mathrm{HP}-\gamma-\mathrm{CD}$ & & Patro et al. (2013) \\
\hline & & $\gamma-\mathrm{CD}$ & & Tønnesen, Másson, and Loftsson (2002) \\
\hline \multirow[t]{14}{*}{ Phenolic acid } & Caffeic acid & $\begin{array}{l}\beta-C D \\
H P-\beta-C D\end{array}$ & Solubility & $\begin{array}{l}\text { Divakar and Maheswaran (1997) } \\
\text { Zhang, Li, Zhang, and Chao (2009) }\end{array}$ \\
\hline & Catechol & $\beta-C D$ & & $\begin{array}{l}\text { Divakar and Maheswaran (1997) } \\
\text { Górnas, Neunert, Baczyński, and Polewski (2009) }\end{array}$ \\
\hline & Chlorogenic acid & $\beta-C D$ & $\begin{array}{l}\text { Solubility } \\
\text { Anti-oxidant } \\
\text { Anti-microbial }\end{array}$ & Zhao, Wang, Yang, \& Tao (2010) \\
\hline & Coumaric acid & $\beta-C D$ & $\begin{array}{l}\text { Solubility } \\
\text { Anti-oxidant }\end{array}$ & Stražišar, Andrenšek, and Šmidovnik (2008) \\
\hline & Ferulic acid & $\alpha-C D$ & Solubility & Divakar and Maheswaran (1997) \\
\hline & & $\beta-C D$ & Photostability & Monti et al. (2011) \\
\hline & & $\gamma-C D$ & Transdermal permeation & Anselmi et al. (2008) \\
\hline & & & & Casolaro, Anselmi, and Picciocchi (2005) \\
\hline & Nerolidylcatechol & $\mathrm{HP}-\beta-\mathrm{CD}$ & Solubility & Soares et al. (2009) \\
\hline & Rosmarinic acid & $\beta-C D$ & Solubility & Celik, Ozyürek, Tufan, Güçlü, and Apak (2011) \\
\hline & & $\mathrm{HP}-\beta-\mathrm{CD}$ & Anti-oxidant & \\
\hline & & HE- $\beta-C D$ & & \\
\hline & & $M-\beta-C D$ & & \\
\hline & Vanillin & $\beta-C D$ & & Divakar and Maheswaran (1997) \\
\hline \multirow[t]{6}{*}{ Stilbenes } & Resveratrol & $\alpha-\mathrm{CD}$ & Thermal stability solubility & Li, Xu, Liu, Sun, and Li (2010) \\
\hline & & $\beta-C D$ & Anti-oxidant & Li et al. (2011) \\
\hline & & $\mathrm{HP}-\beta-\mathrm{CD}$ & Anti-carcinogenic & Lu, Cheng, Hu, Zhang, and Zou (2009) \\
\hline & & $M-\beta-C D$ & UV degradation & Lu, Chen, Fu, Xiong, and Hu (2011) \\
\hline & & $D M-\beta-C D$ & & Kumpugdee-Vollrath (2012) \\
\hline & & $\gamma-\mathrm{CD}$ & & Sapino, Carlotti, Caron, Ugazio, and Cavalli (2008) \\
\hline \multirow[t]{2}{*}{ Flavon-3-ols } & Epigallocatechingallate & $\beta-C D$ & Solubility & Folch-Cano, Guerrero, Speisky, Jullian, and Olea-Azar (2013) \\
\hline & & $\begin{array}{l}\mathrm{HP}-\beta-\mathrm{CD} \\
\mathrm{DM}-\beta-\mathrm{CD}\end{array}$ & Anti-oxidant & \\
\hline \multirow[t]{21}{*}{ Flavone } & Apigenin & DM- $\beta-C D$ & Solubility & Kim, Kim, and Jung (2008) \\
\hline & & $H P-\beta-C D$ & & \\
\hline & Baicalein & $\alpha-C D$ & Solubility & Zhou, Wei, Dou, Chou, \& Wang (2013) \\
\hline & & $\beta-C D$ & Thermal stability & \\
\hline & & $\mathrm{HP}-\beta-\mathrm{CD}$ & & \\
\hline & & DM- $\beta-C D$ & & \\
\hline & & $\gamma-\mathrm{CD}$ & & \\
\hline & Chrysin & $\beta-C D$ & Solubility & Chakraborty, Basu, Lahiri, and Basak (2010) \\
\hline & & $D M-\beta-C D$ & Anti-oxidant & Kim et al. (2008) \\
\hline & & $H P-\beta-C D$ & & \\
\hline & Luteolin & $\beta-C D$ & Solubility & Liu et al. (2013) \\
\hline & & $M-\beta-C D$ & & Kim et al. (2008) \\
\hline & & $D \mathrm{M}-\beta-\mathrm{CD}$ & & \\
\hline & & $\mathrm{HP}-\beta-\mathrm{CD}$ & & \\
\hline & & $\mathrm{HE}-\beta-\mathrm{CD}$ & & \\
\hline & & $G_{2}-\beta-C D$ & & \\
\hline & Rutin & $H P-\alpha-C D$ & Solubility & Calabrò et al. (2005) \\
\hline & & $\beta-C D$ & Stability & Miyake et al. (2000) \\
\hline & & $\mathrm{HP}-\beta-\mathrm{CD}$ & Anti-oxidant & Shuang, Pan, Guo, Cai, and Liu (1997) \\
\hline & & $\gamma-\mathrm{CD}$ & Bioavailability & Nguyen, Liu, Zhao, Thomas, and Hook (2013) \\
\hline & & $\mathrm{HP}-\gamma-\mathrm{CD}$ & & Sri, Kondaiah, Ratna, and Annapurna (2007) \\
\hline \multirow[t]{8}{*}{ Flavonol } & Catechin & $\beta-C D$ & Solubility & Dias, Nikolaou, and Giovani (2011) \\
\hline & & & Anti-oxidant activity & Krishnaswamy, Orsat, and Thangavel (2012) \\
\hline & & & Transdermal permeation & Schwingel et al. (2008) \\
\hline & Galangin & $H P-\beta-C D$ & Solubility & Kim, Choi, and Jung (2009) \\
\hline & & $D M-\beta-C D$ & & \\
\hline & Isoquercetin & $\beta-C D$ & & Wang et al. (2009) \\
\hline & & $\mathrm{HP}-\beta-\mathrm{CD}$ & & \\
\hline & & $D M-\beta-C D$ & & \\
\hline
\end{tabular}




\begin{tabular}{|c|c|c|c|c|}
\hline & Polyphenolic & $\mathrm{CD}$ & Improved characteristics & References \\
\hline & \multirow[t]{4}{*}{ Kaempferol } & $\beta-C D$ & Solubility & Mercader-Ros et al. (2010a,b) \\
\hline & & $G_{2}-\beta-C D$ & Stability & Jullian, Brossard, Gonzalez, Alfaro, and Olea-Azar (2011) \\
\hline & & $\mathrm{HP}-\beta-\mathrm{CD}$ & Thermal stability & Kim et al. (2009) \\
\hline & & $D M-\beta-C D$ & Anti-oxidant activity & Mercader-Ros et al. (2010a,b) \\
\hline & \multirow[t]{2}{*}{ Myricetin } & $\mathrm{HP}-\beta-\mathrm{CD}$ & Solubility & Kim et al. (2009) \\
\hline & & $D M-\beta-C D$ & Anti-oxidant activity & Mercader-Ros et al. (2010a,b) \\
\hline & \multirow[t]{5}{*}{ Quercetin } & $\beta-C D$ & Solubility & Dias et al. (2011) \\
\hline & & $\mathrm{HP}-\beta-\mathrm{CD}$ & Anti-oxidant activity & Sri et al. (2007) \\
\hline & & $M-\beta-C D$ & Photostability & Kim et al. (2009) \\
\hline & & $D M-\beta-C D$ & & Carlotti, Sapino, Ugazio, and Caron (2010) \\
\hline & & & & Mercader-Ros et al. (2010a,b) \\
\hline \multirow[t]{12}{*}{ Flavanone } & \multirow[t]{2}{*}{ Alpinetin } & \multirow[t]{2}{*}{$\mathrm{HP}-\beta-\mathrm{CD}$} & Solubility & \multirow[t]{2}{*}{ Ma et al. (2012) } \\
\hline & & & Stability & \\
\hline & \multirow[t]{3}{*}{ Astilbin } & $\alpha-C D$ & Solubility & \multirow{3}{*}{ Zhang et al. (2013) } \\
\hline & & $\beta-C D$ & & \\
\hline & & $\gamma-C D$ & & \\
\hline & \multirow[t]{4}{*}{ Naringenin } & $\beta-C D$ & Solubility & \multirow{4}{*}{$\begin{array}{l}\text { Yang et al. (2013) } \\
\text { Ficarra et al. (2002) } \\
\text { Shulman et al. (2011) }\end{array}$} \\
\hline & & $\mathrm{HP}-\beta-\mathrm{CD}$ & Bioavailability & \\
\hline & & $D M-\beta-C D$ & & \\
\hline & & TM- $\beta-C D$ & & \\
\hline & Naringin & $\beta-C D$ & Solubility & Ficarra et al. (2002) \\
\hline & Hesperetin & $\beta-C D$ & Solubility & Ficarra et al. (2002) \\
\hline & Hesperidin & $\beta-C D$ & Solubility & Ficarra et al. (2002) \\
\hline \multirow[t]{11}{*}{ Isoflavane } & \multirow[t]{4}{*}{ Daidzein } & $\beta-C D$ & Solubility & \multirow{4}{*}{$\begin{array}{l}\text { Yatsu et al. (2013) } \\
\text { Daruházi et al. (2013) }\end{array}$} \\
\hline & & $\mathrm{HP}-\beta-\mathrm{CD}$ & Bioavailability & \\
\hline & & $\mathrm{RM}-\beta-\mathrm{CD}$ & & \\
\hline & & $\gamma-\mathrm{CD}$ & & \\
\hline & \multirow[t]{4}{*}{ Genistein } & $\beta-C D$ & Solubility & \multirow{4}{*}{$\begin{array}{l}\text { Yatsu et al. (2013) } \\
\text { Daruházi et al. (2013) }\end{array}$} \\
\hline & & $\mathrm{HP}-\beta-\mathrm{CD}$ & Bioavailability & \\
\hline & & $R M-\beta-C D$ & & \\
\hline & & $\gamma-\mathrm{CD}$ & & \\
\hline & \multirow[t]{2}{*}{ Glycitein } & $\beta-C D$ & Solubility & \multirow[t]{2}{*}{ Yatsu et al. (2013) } \\
\hline & & $\mathrm{HP}-\beta-\mathrm{CD}$ & & \\
\hline & Puerarin & $\mathrm{G}_{2}-\beta-\mathrm{CD}$ & Solubility & Liu, Zhao, Liu, Zhu, and Zeng (2012) \\
\hline
\end{tabular}

already mentioned for rutin (Chakraborty et al., 2010; Kim et al., 2008).

As the most part of flavonoids, quercetin is flavonol with antibacterial, antioxidant and antitumor properties but its use on the pharmaceutical field is limited due to it sparingly solubility in water (Jullian, Moyano, Yañez, \& Olea-Azar, 2007). The $\beta-C D$ was used to improve solubility and photo stability of quercetin by several authors (Calabrò et al., 2004; Jullian et al., 2007; Sri et al., 2007). Jullian et al. (2007) and Calabrò et al. (2004) reported a 1:1 stochiometric complex, but Sri et al. (2007) described a 1:2 complex. As it was mentioned in Section 2.1, in the same equilibrium, it is possible to find different interactions between $C D$ and the guest molecule (1:1 or 2:1). Moreover, the $K$ values, assessed by these authors, rise with the increase of the temperature. Jullian et al. (2007) used $30^{\circ} \mathrm{C}$ to prepare the quercetin- $\beta-\mathrm{CD}$ and had the higher stability constant $\left(602 \mathrm{M}^{-1}\right)$. In the same work, the IC formation with SBE- $\beta-C D$ and HP- $\beta-C D$ was also established. The IC for both $\beta-C D$ derivatives with quercetin was $1: 1$ and the solubility of quercetin was enhanced, with $K$ of 4032 and $1419 \mathrm{M}^{-1}$, respectively, without diminishing its antioxidant property. Moreover, the CD derivatives were more efficient on the solubilisation of quercetin than the natural CD (Fig. 7) and showed better antioxidant activity (Jullian et al., 2007). The HP- $\beta$-CD was also used by Sri et al. (2007) and by Mercader-Ros et al. (2010a,b) to enhance the solubility and antioxidant properties of the quercetin. In both situations, the $K$ value found was lower $\left(321\right.$ and $\left.900 \mathrm{M}^{-1}\right)$ than that mentioned by Jullian et al., as well as the temperature used (28 and $25^{\circ} \mathrm{C}$ ) (Mercader-Ros et al., 2010a,b; Sri et al., 2007), this means that the temperature is a crucial parameter on quercetin/HP$\beta$-CD IC formation. The antioxidant activity of the quercetin was improved by its encapsulation by $\beta-C D$ derivatives (HP- $\beta-C D$, SBE$\beta-C D$, DM- $\beta-C D$ and M- $\beta-C D$ ) (Carlotti et al., 2010; Jullian et al.,
2007; Mercader-Ros et al., 2010a,b; Yu et al., 2007). The enhancement of quercetin biological activity may be an outcome of the protection from the rapid oxidation by free radicals conferred by the CDs (Mercader-Ros et al., 2010a,b). Carlotti et al. (2010) also reduced the photodegradation ratio of the quercetin by its complexation with $\mathrm{M}-\beta-\mathrm{CD}$. They claimed that because quercetin was in an apolar environment inside the $\mathrm{CD}$ cavity the photolytic reaction was reduced, and the amount of light capable of reach this flavonol was lower, since it had to cross the CD molecule (Carlotti et al., 2010).

Kaempferol is also a flavonol with great interest in the pharmaceutical field due to its potent antioxidant activity (Havsteen, 2002). Its behaviour in aqueous environment had been improved by the utilisation of CDs as encapsulating agents. As the other works described above, the $\beta-C D$ derivatives, such as HP- $\beta-C D$, DM- $\beta-C D$ and G2- $\beta-C D$, were more suitable for the IC formation with kaempferol than the $\beta-C D$ (Jullian, Brossard, Gonzalez, Alfaro, \& Olea-Azar, 2011; Kim, Choi, \& Jung, 2009; Mercader-Ros et al., 2010a,b). Additionally, the temperature conditions the $K$ values, but in this situation IC formation was improved by lower temperatures (Jullian et al., 2011). The beneficial effect of the IC on the antioxidant activity of kaempferol was determined by Kim et al. (2009) and Mercader-Ros et al. (2010a,b).

The naringenin is a flavanone with a similar structure of the rutin, with good antioxidant capacity and capable of reduce the cholesterol plasma level (Goldwasser, 2010). The formation of IC between naringenin and $\beta-C D$ and its derivatives (HP- $\beta-C D, D M-$ $\beta-C D, M-\beta-C D$ and $T M-\beta-C D)$ was analysed by several authors (Ficarra et al., 2002; Shulman et al., 2011; Yang et al., 2013). For the CDs mentioned above the stoichiometry of the IC was $1: 1$, and the HP- $\beta-C D$ was the CD with higher stability constant (Shulman et al., 2011). Yang et al. (2013) demonstrated that the water 

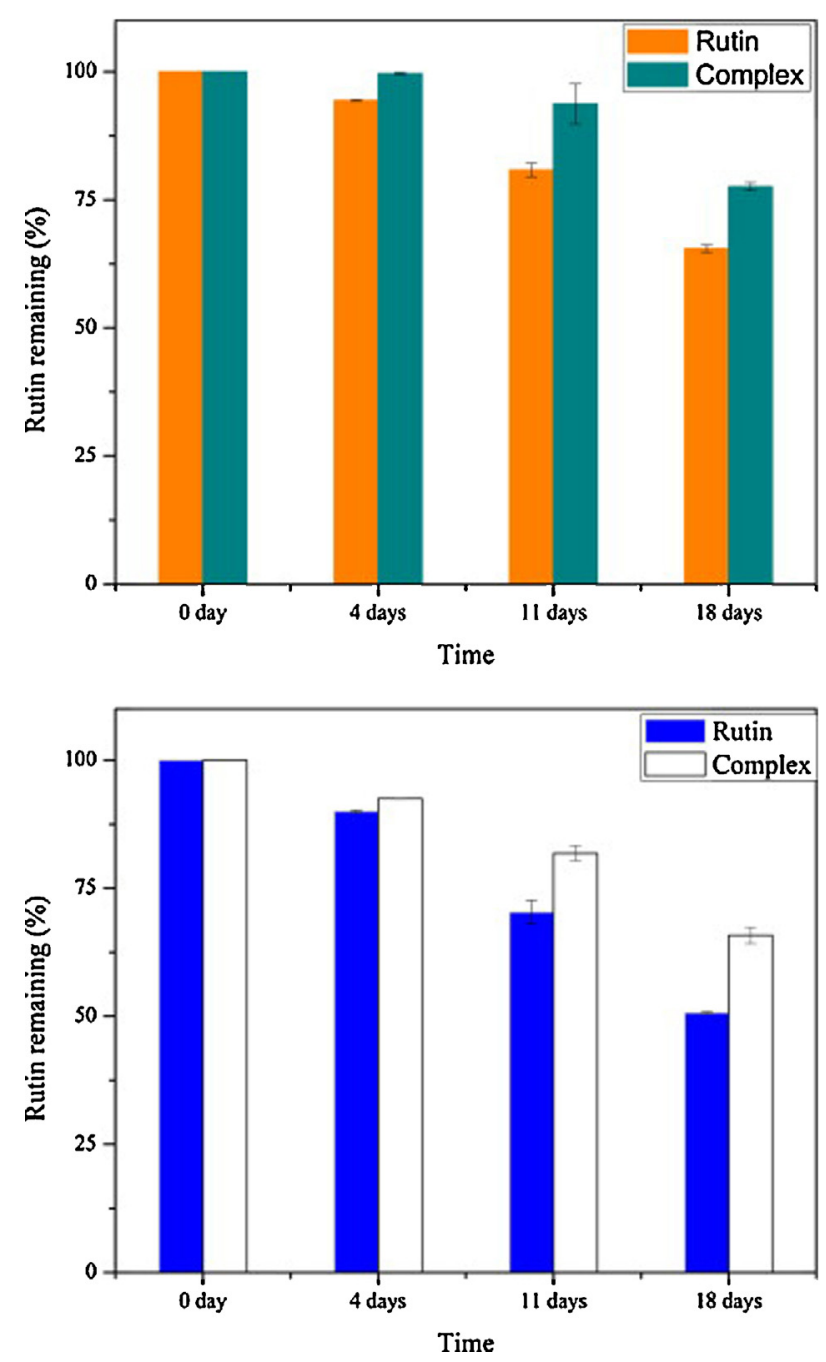

Fig. 6. Degradation of rutin by UV radiation (top) and heat (bottom) during an 18day storage period (Nguyen, Liu, Zhao, Thomas, \& Hook, 2013).

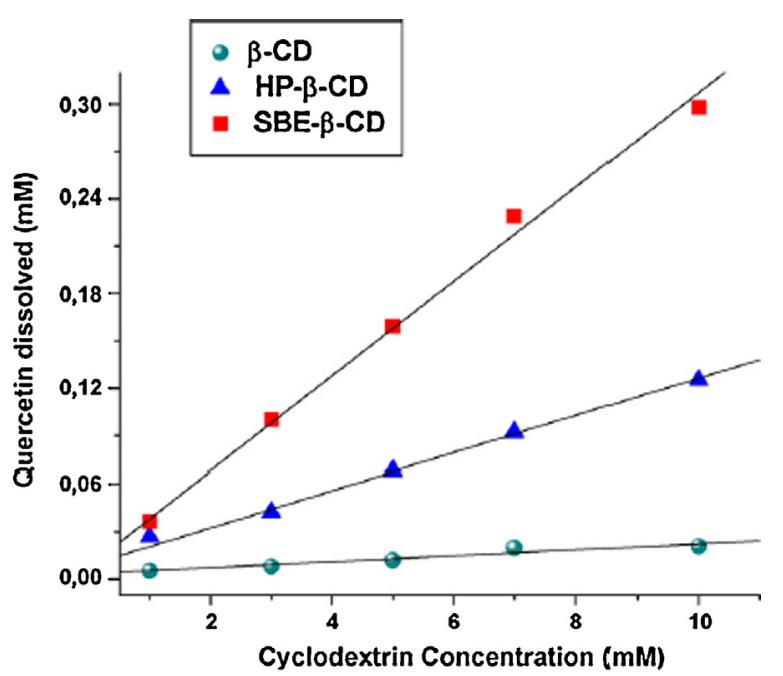

Fig. 7. Phase-solubility diagrams of quercetin IC with $\beta-C D, S B E-\beta-C D$ and $H P-\beta-C D$ in water at $30^{\circ} \mathrm{C}$ (Jullian, Moyano, Yañez, \& Olea-Azar, 2007). solubility and thermal stability of this flavonoid was improved when encapsulated by $\beta-C D$, DM- $\beta-C D$ or TM- $\beta-C D$ spectrum. In fact, the ICs remained stable when exposed to temperatures near $225^{\circ} \mathrm{C}$. Based on their analysis of the NMR, they assumed that the $\mathrm{C}$ ring of naringenin was interacting with the CDs' cavity (Yang et al., 2013). The biological effect of the IC naringenin/HP- $\beta-C D$ was also described. Shulman and co-workers proved that the solubility of the flavonoid was increased 400 times when complexed with the $\mathrm{HP}-\beta-\mathrm{CD}$; moreover the naringenin transport across the model of the gut epithelium (Caco-2 cells) was also enhanced as well as its plasma concentration. Therefore, the IC naringenin/HP- $\beta-C D$ can be used as oral delivery drug for the treatment of diabetes and dyslipidaemia (Shulman et al., 2011).

Ficarra et al. (2002) and Tommasini et al. (2005) investigated the effect of the $\beta-C D$ and HP- $\beta-C D$ IC on the solubility of the flavanones hesperetin and hesperidin. In the first work, hesperetin and hesperidin were complexed with $\beta-\mathrm{CD}$ and improvement on the solubility and chemical stability was demonstrated (Ficarra et al., 2002). Tommasini et al. (2005) demonstrated that the ICs formed was $1: 1$, and the better complexation was observed by HP$\beta-C D$ and hesperetin, based on the higher $K$ values $\left(21,000 \mathrm{M}^{-1}\right)$ when compared to the ones assessed for hesperidin $\left(K 90 \mathrm{M}^{-1}\right)$. The $K$ values discrepancy can be justified by the size of the flavanones molecules, the hesperetin is smaller and less polar which make it more appropriate to interact with the hydrophobic cavity of the $C D$ derivative. Nevertheless, the solubility of both flavanones was improved and, consequently, their antioxidant activity (Fig. 8). Therefore, the hesperidin and hesperetin application as antioxidant and anti-carcinogenic can be upgraded by the use of HP- $\beta-C D$ as drug delivery agent (Tommasini et al., 2005).

Yang et al. (2011) used the three native CD and HP- $\beta-C D$ for the IC formation with taxifolin, a flavanonol able to dilate blood vessels, enhance microcirculation and cerebral blood flow and prevent platelet aggregation. In this investigation, they proved that the ICs formed enhanced the taxifolin water solubility and thermal stability, highlighting their use on healthcare products. Moreover, $\beta-C D$ showed better capacity to interact with this flavanonol (Yang et al., 2011).

The genistein is an isoflavone used on treatment and prevention of estrogenic related cancers or postmenopausal symptoms due to its great affinity to estrogenic receptors. This polyphenolic had also anti-inflammatory effects and platelet aggregation inhibition. However, genistein limited solubility reduce its applicability in the pharmaceutical industry (Daruházi et al., 2013). The complexation of genistein with $\mathrm{CD}$ can improve its solubility and enhance its biological effects. Daruházi et al. (2013) tested the IC formation between this isoflavonoid and $\beta-C D, \gamma-C D, H P-$ $\beta-C D$ and $R M-\beta-C D$. The genistein was capable of interacting with the $4 \mathrm{CD}$, but the $\mathrm{CD}$ derivatives induced a higher influence on the solubility of the compounds. The genistein capacity to cross biological membranes was also improved by the encapsulation with the CDs (Fig. 9) (Daruházi et al., 2013). Yatsu et al. (2013) assessed the $\beta-C D$ and HP- $\beta-C D$ encapsulation capacity of a mixture of daidzein, genistein and glycitei. All the isoflavones showed higher affinity to the HP- $\beta-C D$ and the interaction between the $\mathrm{CD}$ and the bioactive molecules occur by introduction of the B-ring into the CD cavity, besides external interactions (Yatsu et al., 2013). Based on the works described above, the derivatives of $\beta-C D$ are more appropriate for the improvement of the flavonoids solubilisation and stabilisation, being the HP- $\beta-C D$ the most used. These groups of flavonoids can interact with CDs by (1) directing the B-ring towards the secondary rim of the $C D$ or (2) heading the A-ring towards the secondary rim of the CD (Kim et al., 2009). Moreover, flavonoids photo- and thermal stability upgrade by encapsulation with CDs, as well as their antioxidant 


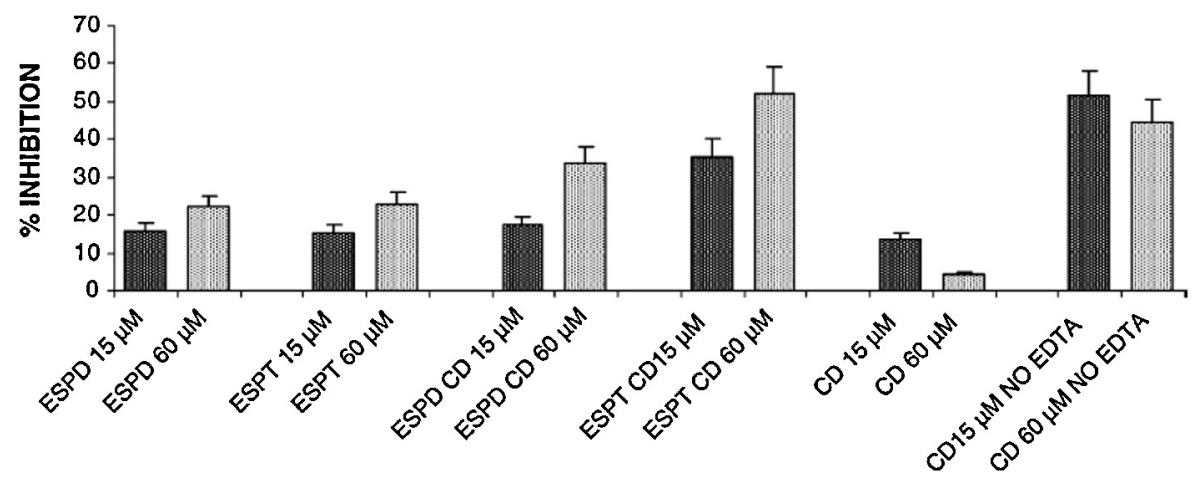

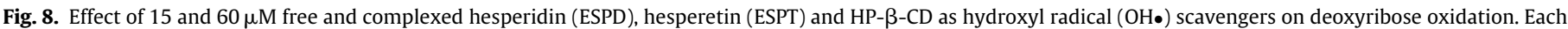

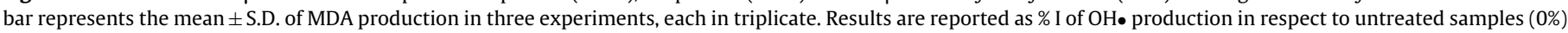
(Tommasini et al., 2005).

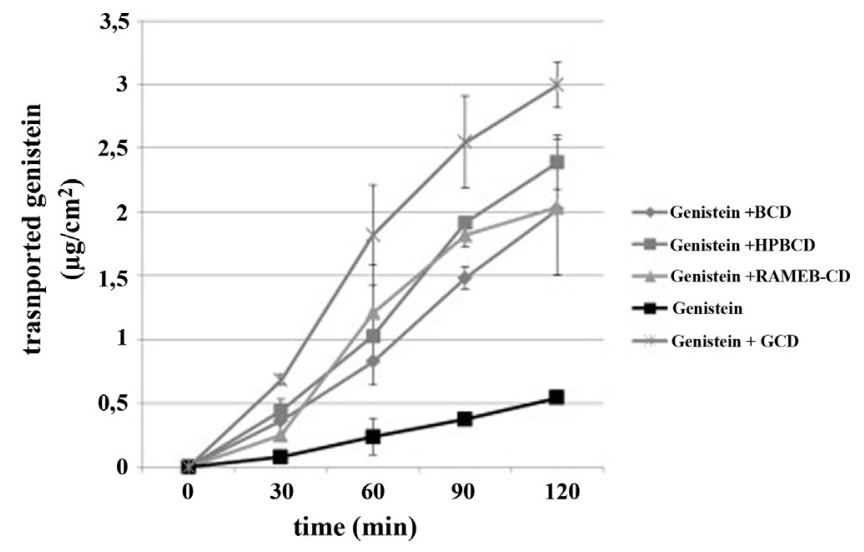

Fig. 9. Transport of genistein and its $\beta-C D, \gamma-C D, H P-\beta-C D$, and RAMEB-CD complexes through Caco-2 monolayer (Daruházi et al., 2013).

activity, since the CDs prevent the oxidation by free radical of the flavonoids.

\subsection{CDs and non-flavonoids}

As referred above, the non-flavonoids had great importance on the pharmaceutical and cosmetic industry due to their biological properties. Though, their application is limited because these polyphenolics are very susceptible to degradation by environmental factors such as light, temperature and pH (Crozier et al., 2009; Del Rio, Costa, Lean, \& Crozier, 2010). In order to overcome this, some works have been published regarding the inclusion of nonflavonoids into $\mathrm{CD}$.

The ferulic acid is commonly used for the preventing UV light induced skin tumour, but it has low stability under thermal and physical stress. The IC formation between ferulic acid and $\alpha-C D$ was investigated by Anselmi et al. (2008). Thus, the authors proposed the inclusion of this phenolic acid into the $\alpha-C D$, with a $K$ value of $1162 \mathrm{M}^{-1}$ and equimolecular complexation. Based on their results, the $\alpha$ and $\beta$ unsaturated part of the ferulic acid and part of its aromatic skeleton were inside the hydrophobic cavity of the $\mathrm{CD}$. The IC increased the ferulic acid resistance to the degradation by UVB and also, decreases its rate release (Anselmi et al., 2008). The same phenolic acid was used by Casolaro, Anselmi, \& Picciocchi (2005) for the complexation with $\alpha-\mathrm{CD}$. The stoichiometry of the IC was the same and they assumed that the ferulic acid was neutralised inside the CD cavity (Casolaro et al., 2005). The cutaneous permeation and distribution through skin of the IC ferulic acid and $\alpha-C D$ was assessed by Monti et al. (2011). They concluded that the IC prevented the formation of the less active cis-isomer of ferulic acid and its degradation by UV light. The ferulic acid/ $\alpha-C D$ IC presented lower penetration on the skin which enlarge the skin protection against UV damages, since the ferulic acid remains at the skin surface (Monti et al., 2011). The encapsulation of ferulic acid with HP- $\beta$-CD was also studied (Wang, Cao, Sun, \& Wang, 2011). The IC obtained had lower stability $\left(K 166.3 \mathrm{M}^{-1}\right)$ and the same stoichiometry of the other ICs described above. Nevertheless, the solubility and protection against decomposition caused by irradiation with UV light was enhanced by the complexation of the ferulic acid with this CD (Wang et al., 2011).

Although, caffeic acid has been described as antibacterial and antioxidant phenolic acid, its biological activity may be jeopardised by its sensibility to oxidation and lower solubility (Zhang, Li, Zhang, \& Chao, 2009). Thus, some authors had described its encapsulation with CD to overcome these issues. Górnas, Neunert, Baczyński, \& Polewski (2009) and Divakar and Maheswaran (1997) complexed this phenolic acid with $\beta$-CD. In both cases, the experimental results suggest a $1: 1 \mathrm{IC}$ with $K$ of 270 and $516 \mathrm{M}^{-1}$. The molecular interaction was described as follows, the hydroxyl groups of the phenolic acid were trapped inside the $\beta-C D$ cavity and the carboxyl moiety was projected outwards the CD (Divakar \& Maheswaran, 1997; Górnas et al., 2009). Górnas et al. (2009) studied the influence of the $\mathrm{pH}$ on the IC formation, and concluded that the $K$ decreased with the presence of caffeic acid charged species. The caffeic acid was, also, encapsulated by HP- $\beta-C D$ to increase solubility (Zhang et al., 2009). The authors conclude that the IC formation was better in acid conditions and the IC ratio was $1: 1$; also, the caffeic acid solubility increases. The lipophilic aromatic ring and ethylene portion of the caffeic acid was entrapped inside the $C D$ cavity and the polar groups were outside the HP- $\beta$-CD cavity (Fig. 10) (Zhang et al., 2009).

Rosmarinic acid, a hydroxycinnamic acid with high antioxidant properties and poor solubility, was encapsulated with $\alpha-C D$, $\beta-C D, H P-\beta-C D, H E-\beta-C D$ and M- $\beta-C D$ (Celik, Ozyürek, Tufan, Güçlü, \& Apak, 2011) in order to improve both properties. By the observation on the UV-Vis spectrum of the rosmarinc acid and the ICs, the authors assessed the stoichiometry of all ICs (1:1) and the $K$. They reported that ability forming stables IC was as follows $M-\beta-C D>H E-\beta-C D>H P-\beta-C D>\beta-C D>\alpha-C D$. Additionally, the antioxidant activity of the ICs was higher than the rosmarinic acid alone (Celik et al., 2011).

Resveratrol trans-3,4,5'-trihydroxystilbene is a polyphenolic with a high level of therapeutic potential as anti-carcinogenic and anti-oxidant (Sapino et al., 2008). This stilbene displays a hydrophobic behaviour, and is also extremely affected by exposure to oxygen, light, and oxidative enzymes, reducing its bioactivity. The use of $C D$ to protect resveratrol and to increase its solubility, stability and bioactivity was applied in several studies (Kumpugdee-Vollrath, 2012; Li, Xu, Liu, Sun, \& Li, 2010; Lu, Cheng, Hu, Zhang, \& Zou, 


\section{(a)}

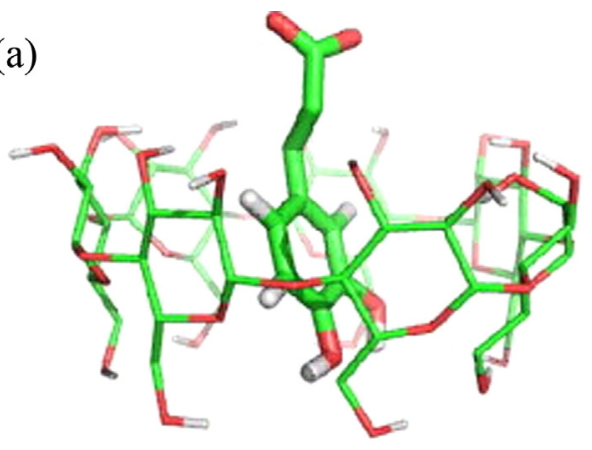

(b)

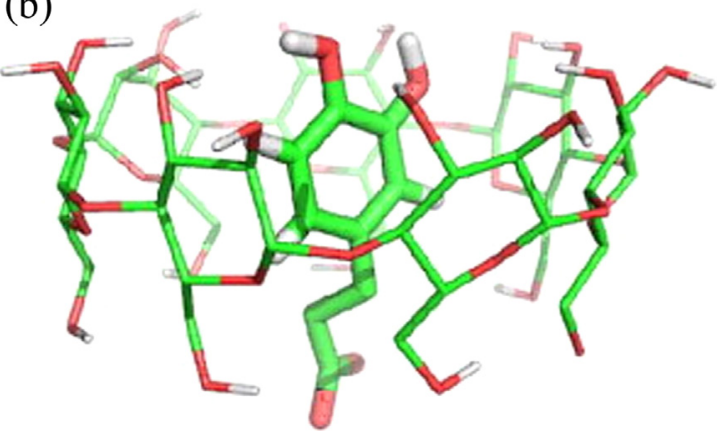

Fig. 10. Optimised structure of the $\beta-C D$-caffeic acid complex. Caffeic acid is inserted into the apolar cavity of betaCD from its (a) "top" side; (b) "bottom" side.

2009; Lu, Chen, Fu, Xiong, \& Hu, 2011; Lucas-Abellán, Fortea, LópezNicolás, \& Núñez-Delicado, 2007; Sapino et al., 2008). The effect of 3 native $C D$ s and $M-\beta-C D$ on the thermal stability of the resveratrol was reported by Li et al. (2010). Based on the thermal analyses made, they assumed that the IC formation was favoured by the temperature rise, since all the reactions had negative enthalpy energy. The encapsulation of $\gamma-\mathrm{CD}$ and resveratrol was the most stable owing to the better fit between the phenolic compound and the CD cavity, since $\gamma$-CD had the biggest cavity (Li et al., 2010). A similar work used the native $\alpha-C D$ and $\beta-C D$ and 2 derivatives (HP- $\beta-C D$ and DM- $\beta-C D$ ) to increase the concentration of resveratrol on solution and its stability. It was observed that the IC with native $C D$ was only capable of complexing with part of the resveratrol molecule and that the HP- $\beta-C D$ offered a cavity with a better fit to the bioactive molecule (Kumpugdee-Vollrath, 2012).

The biological properties of resveratrol (anti-oxidant and anti-carcinogenic) were also enhanced by its encapsulation. For instance, Lu and co-workers used $\beta-C D$ and HP- $\beta-C D$ as resveratrol carrier agents and described the betterment of the scavenging capacity of the IC (Lu et al., 2009), the inhibition of the lipid peroxidation activity (Fig. 11) and the cytotoxicity to cancer cells without harming the healthy ones (Lu et al., 2011). The results obtained on the two works support the notion that the CD derivative forms a stronger IC with this stilbene $\left(K \beta-\mathrm{CD} 1815 \mathrm{M}^{-1}\right.$ and $K$ HP- $\beta-C D 6778 \mathrm{M}^{-1}$ ), related to the easier access of the resveratrol to the HP- $\beta-C D$ cavity due to enlargement of the cavity opening and the despairing of the intramolecular hydrogen bond network (Lu et al., 2011, 2009). Additionally, the employment of HP- $\beta-C D$ for resveratrol encapsulation also increases the photostability of this natural compound. The host position of the 'guest' molecule inside the CDs did increase the resistance to the degradation by UV radiation without affecting its antioxidant properties. Therefore, the resveratrol-HP- $\beta-C D$ ICs represent a powerful candidate for the protection of skin against oxidative stressing episodes (Sapino et al., 2008). Furthermore, resveratrol concentration on aqueous environment was improved by the complexation with $\beta-C D$ and $\mathrm{G}_{2}-\beta-C D$ and, consequently, its antioxidant capacity. Besides the

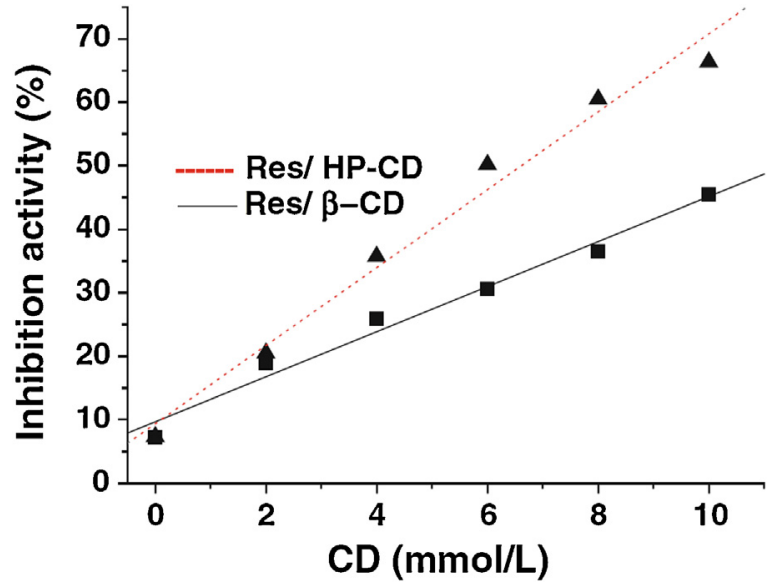

Fig. 11. Inhibition activity of lipid peroxidation of the resveratrol- $\beta-C D$ and resveratrol-HP- $\beta-\mathrm{CD}$ complexes at $25^{\circ} \mathrm{C}$ (Lu, Chen, Fu, Xiong, \& Hu, 2011).

solubilisation, both CDs were capable of protecting the phenolic compound from rapid oxidation, by entrapping it inside their cavities, with similar stability $\left(K \beta-\mathrm{CD} 4317 \mathrm{M}^{-1}\right.$ and $K \mathrm{G}_{2}-\beta-\mathrm{CD}$ $5130 \mathrm{M}^{-1}$ ) (Lucas-Abellán et al., 2007).

The curcumin is a natural phenolic compound with anti-tumour activity and effective against HIV-infection, cystic fibrosis and immunomodulating agent, but their low stability at acid environment and physiological $\mathrm{pH}$ and it photosensibility limited the use of this coumarin as pharmaceutical agent (Aggarwal, Sundaram, Malani, \& Ichikawa, 2007). Therefore, its encapsulation by the native CD was described by Patro et al. (2013). They were able to improve the solubility and oral availability with all the 3 IC; however the $\alpha-C D$ was the one that showed higher $K\left(1124 \mathrm{M}^{-1}\right)$. López-Tobar et al. (2012) also applied to $\beta$-CD and $\gamma$-CD as curcumin drug carriers. The large cavity of $\gamma$-CD was more efficient in the IC formation. Moreover, both CDs were able to form 2:1 IC with this phenolic compound and the molecular interaction proposed was that the aromatic rings and the hydrogen bonds were involved and a change occurs from the curcumin planar ketoenol form to non-planar diketo. The chemical stability and bioavailability may be upgraded by this conformational alteration (López-Tobar, Blanch, Ruiz del Castillo, \& Sanchez-Cortes, 2012). The same stoichiometry of the IC $\beta$-CD-curcumin was observed by Tang, Ma, Wang, and Zhang (2002) and Rahman, Cao, Steadman, Wei, \& Parekh (2012). In both situations, the solubility of curcumin was described as well as the same molecular interaction, as referred above. Dandawate et al. (2012) used a synthetic form of curcumin but accomplished the same stoichiometry and solubility. In this work, the anti-carcinogenic, systemic bioavailability and tissue distribution of the IC $\beta-C D$-synthetic curcumin were compared with the synthetic curcumin alone and concluded that they have been improved by the encapsulation (Dandawate et al., 2012).

CD derivatives were also tested as drug carriers of curcumin, in order to overcome the difficulties of its application as anti-carcinogenic agent. For instance, 2 molecules of HP- $\beta-C D$ formed stable IC ( $\left.K 5000-62,000 \mathrm{M}^{-1}\right)$ with 1 molecule of curcumin (Ghanghoria, Kesharwani, Agashe, \& Jain, 2012; Mohan, Sreelakshmi, Muraleedharan, \& Joseph, 2012; Tomren, Másson, Loftsson, \& Tønnesen, 2007). The transdermal capacity of curcumin was raised by the complexation with HP- $\beta-C D$ as well as the decrease of skin irritation (Ghanghoria et al., 2012). Besides, HP- $\beta-C D, H P-\alpha-C D$ and HP- $\gamma-C D$ were used with the same goal. Mohan et al. (2012) compared the encapsulation of the three CD derivatives and reported that the encapsulation may occur both in $1: 1$ and $2: 1$ stoichiometry and the HP- $\gamma$-CD has a better complexion capacity. This IC (HP- $\gamma$-CD-curcumin) was capable of reducing 
cell proliferation and increases the apoptosis of cancer cells by interfering in the protein production (Rocks et al., 2012). Tønnesen, Másson, \& Loftsson (2002) reported the encapsulation of curcumin with several $C D$ derivatives, namely HP- $\alpha-C D, R M-\beta-C D, H P-\beta-C D$, SBE- $\beta-C D$, HTA- $\beta-C D$ and HP- $\gamma-C D$. The greater positive change on the stability and solubility of curcumin was achieved by the complexation with the RM- $\beta-C D$ and $H P-\gamma-C D$, probably due to the more hydrophobic environment found inside the cavity of the first $\mathrm{CD}$ and large cavity of the second leading to a better accommodation of the bioactive molecule (Tønnesen et al., 2002). The increase of the curcumin resistance to hydrolysis under alkaline environments when encapsulated with these CDs, was also proved (Tønnesen et al., 2002).

The application of CDs as carriers of non-flavonoids is a viable choice to protect them from degradation by environment factures, such as UV-light, $\mathrm{pH}$, temperature and oxidation, and also to improve their solubility, factors that contribute to increase the biological properties of these natural active molecules. However, because this group of molecules is a bit diverse, it is not possible to generalise the molecular mechanisms of interaction between CDs and non-flavonoids and the efficiency of the encapsulation depends, essentially, on the size of the CD cavity.

\section{Conclusion}

The use of bioactive molecules from plants has gained a substantial interest during the last decade for food, cosmetic and pharmaceutical applications. Polyphenolic agents derived from plant sources have aroused much interest, especially in view of their antioxidant activity and bactericidal and fungicidal actions. Concerning the pharmaceutical applications of these plant-derived bioactive molecules, the current problems are related to the protection of their properties from environmental factors, with their solubility in water and biofluids, and their bioavailability.

CDs have a relatively unique capacity of improving solubility of bioactive polyphenolic agents in aqueous systems; protect them from elevated temperatures, $\mathrm{pH}$ values, light or the moistureinduced degradations phenomena which serve to increase their bioavailability. Furthermore, the use of substituted cyclodextrins has been found to improve the physicochemical properties of these bioactive molecules. In fact, in the case of flavonoids the CD'derivatives are the better choice to achieve an efficient complexation. Otherwise, the selection of the better CD for encapsulated non-flavonoids molecules needs to be based on the dimensions of the molecule and the CD' cavity.

Nevertheless, the formation of inclusion complexes between CDs and plant polyphenolics serves as a promising pathway for the development of pharmaceutical products friendlier to the user.

\section{Conflict of interest}

\section{None declared.}

\section{Acknowledgments}

The authors thank the Foundation for Science and Technology (Portugal) for financial support to the CEB research center and E. Pinho grant (SFRH/BD/62665/2009) and also to FEDER through Programa Operacional Factores de Competitividade - COMPETE and by national funds by FCT - Fundação para a Ciência e a Tecnologia in the context of project PEst-C/CTM/UI0264/2011.

\section{References}

Aggarwal, B. B., Sundaram, C., Malani, N., \& Ichikawa, H. (2007). Curcumin: The Indian solid gold. Advances in Experimental Medicine and Biology, 595, 1-75. http://dx.doi.org/10.1007/978-0-387-46401-5_1
Alberto, M. R., Farías, M. E., \& Nadra, M. C. (2001). Effect of gallic acid and catechin on lactobacillus hilgardii $5 \mathrm{w}$ growth and metabolism of organic compounds. Journal of Agricultural and Food Chemistry, 49(9), 4359-4363. http://dx.doi.org/10.1021/jf0101915

Anselmi, C., Centini, M., Maggiore, M., Gaggelli, N., Andreassi, M., Buonocore, A., et al. (2008). Non-covalent inclusion of ferulic acid with alphacyclodextrin improves photo-stability and delivery: NMR and modeling studies. Journal of Pharmaceutical and Biomedical Analysis, 46(4), 645-652. http://dx.doi.org/10.1016/j.jpba.2007.11.037

Aqil, F., Munagala, R., Jeyabalan, J., \& Vadhanam, M. V. (2013). Bioavailability of phytochemicals and its enhancement by drug delivery systems. Cancer Letters, 334(1), 133-141. http://dx.doi.org/10.1016/j.canlet.2013.02.032

Aridogan, B., Baydaf, H., Kaya, S., Demirci, M., Ozbaw, D., \& Mumcu, E. (2002). Antimicrobial activity and chemical composition of some essential oils. Archives of Pharmacal Research, 25(6), 860-864.

Arun, R., Ashok, K. C. K., Sravanthi, V. V. N. S. S., Rasheed, A., Kumar, A. C. K., \& Saravanthi, V.V. N. S. S. (2008). Cyclodextrins as drug carrier molecule: A review. Scientia Pharmaceutica, 76(4), 567-598. http://dx.doi.org/10.3797/scipharm.0808-05

Belščak-Cvitanović, A., Stojanović, R., Manojlović, V., Komes, D., Cindrić, I. J., Nedović, V., et al. (2011). Encapsulation of polyphenolic antioxidants from medicinal plant extracts in alginate-chitosan system enhanced with ascorbic acid by electrostatic extrusion. Food Research International, 44(4), 1094-1101. http://dx.doi.org/10.1016/j.foodres.2011.03.030

Buschmann, H.-J., \& Schollmeyer, E. (2002). Applications of cyclodextrins in cosmetic products: A review. Journal of Cosmetic Science, 53(3), 185-191. Retrieved from http://www.ncbi.nlm.nih.gov/pubmed/12053209.

Cal, K., \& Centkowska, K. (2008). Use of cyclodextrins in topical formulations: Practical aspects. European Journal of Pharmaceutics and Biopharmaceutics, 68(3), 467-478. http://dx.doi.org/10.1016/j.ejpb.2007.08.002

Calabrò, M. L., Tommasini, S., Donato, P., Raneri, D., Stancanelli, R., Ficarra, P., et al. (2004). Effects of alpha- and beta-cyclodextrin complexation on the physico-chemical properties and antioxidant activity of some 3hydroxyflavones. Journal of Pharmaceutical and Biomedical Analysis, 35(2), 365-377. http://dx.doi.org/10.1016/j.jpba.2003.12.005

Calabrò, M. L., Tommasini, S., Donato, P., Stancanelli, R., Raneri, D., Catania, S., et al. (2005). The rutin/beta-cyclodextrin interactions in fully aqueous solution: Spectroscopic studies and biological assays. Journal of Pharmaceutical and Biomedical Analysis, 36(5), 1019-1027. http://dx.doi.org/10.1016/j.jpba.2004.09.018

Carlotti, M. E., Sapino, S., Ugazio, E., \& Caron, G. (2010). On the complexation of quercetin with methyl- $\beta$-cyclodextrin: Photostability and antioxidant studies. Journal of Inclusion Phenomena and Macrocyclic Chemistry, 70(1/2), 81-90. http://dx.doi.org/10.1007/s10847-010-9864-7

Casolaro, M., Anselmi, C., \& Picciocchi, G. (2005). The protonation thermodynamics of ferulic acid $/ \gamma$-cyclodextrin inclusion compounds. Thermochimica Acta, 425(1/2), 143-147. http://dx.doi.org/10.1016/j.tca.2004.06.016

Celik, S. E., Ozyürek, M., Tufan, A. N., Güçlü, K., \& Apak, R. (2011). Spectroscopic study and antioxidant properties of the inclusion complexes of rosmarinic acid with natural and derivative cyclodextrins. Spectrochimica Acta Part A: Molecular and Biomolecular Spectroscopy, 78(5), 1615-1624. http://dx.doi.org/10.1016/j.saa.2011.02.017

Chakraborty, S., Basu, S., Lahiri, A., \& Basak, S. (2010). Inclusion of chrysin in $\beta$ cyclodextrin nanocavity and its effect on antioxidant potential of chrysin: A spectroscopic and molecular modeling approach. Journal of Molecular Structure, 977(1-3), 180-188. http://dx.doi.org/10.1016/j.molstruc.2010.05.030

Cowan, M. M. M. (1999). Plant products as antimicrobial agents. Clinical Microbiology Reviews, 12(4), 564. Retrieved from http://cmr.asm.org/content/12/4/564.short.

Creaven, B. S., Czeglédi, E., Devereux, M., Enyedy, É. A., Foltyn-Arfa Kia, A., Karcz, D., et al. (2010). Biological activity and coordination modes of copper(II) complexes of Schiff base-derived coumarin ligands. Dalton Transactions (Cambridge, England: 2003), 39(45), 10854-10865. http://dx.doi.org/10.1039/c0dt00068j

Crozier, A., Jaganath, I. B., \& Clifford, M. N. (2009). Dietary phenolics: Chemistry, bioavailability and effects on health. Natural Product Reports, 26(8), 1001-1043. http://dx.doi.org/10.1039/b802662a

Cueva, C., Moreno-Arribas, M. V., Martín-Alvarez, P. J., Bills, G., Vicente, M. F., Basilio, A., et al. (2010). Antimicrobial activity of phenolic acids against commensal, probiotic and pathogenic bacteria. Research in Microbiology, 161(5), 372-382. http://dx.doi.org/10.1016/j.resmic.2010.04.006

Dai, J., \& Mumper, R. J. (2010). Plant phenolics: Extraction, analysis and their antioxidant and anticancer properties. Molecules, 15(10), 7313-7352. http://dx.doi.org/10.3390/molecules15107313

Dandawate, P. R., Vyas, A., Ahmad, A., Banerjee, S., Deshpande, J., Swamy, K. V., et al. (2012). Inclusion complex of novel curcumin analogue CDF and $\beta$-cyclodextrin $(1: 2)$ and its enhanced in vivo anticancer activity against pancreatic cancer. Pharmaceutical Research, 29(7), 1775-1786. http://dx.doi.org/10.1007/s11095-012-0700-1

Daruházi, A. E., Kiss, T., Vecsernyés, M., Szente, L., Szőke, E., \& Lemberkovics, E. (2013). Investigation of transport of genistein, daidzein and their inclusion complexes prepared with different cyclodextrins on Caco2 cell line. Journal of Pharmaceutical and Biomedical Analysis, 84C, 112-116. http://dx.doi.org/10.1016/j.jpba.2013.05.012

Davis, M. E., \& Brewster, M. E. (2004). Cyclodextrin-based pharmaceutics: Past, present and future. Discovery, 3(December) http://dx.doi.org/10.1038/ nrd1576

Del Rio, D., Costa, L. G., Lean, M. E. J., \& Crozier, A. (2010). Polyphenols and health: What compounds are involved? Nutrition, Metabolism, and Cardiovascular Diseases: NMCD, 20(1), 1-6. http://dx.doi.org/10.1016/j.numecd.2009.05.015 
Del Valle, E. (2004). Cyclodextrins and their uses: A review. Process Biochemistry, 39(9), 1033-1046. http://dx.doi.org/10.1016/S0032-9592(03)00258-9

Dhule, S. S., Penfornis, P., Frazier, T., Walker, R., Feldman, J., Tan, G., et al. (2012). Curcumin-loaded $\gamma$-cyclodextrin liposomal nanoparticles as delivery vehicles for osteosarcoma. Nanomedicine: Nanotechnology, Biology, and Medicine, 8(4), 440-451. http://dx.doi.org/10.1016/j.nano.2011.07.011

Dias, K., Nikolaou, S., \& Giovani, W.F.(2011). The in vitro antioxidant properties of the Al-quercetin/BCD and Al-catechin/ $\mathrm{BCD}$ inclusion compounds, rationalized in terms of their electrochemical behaviour. Medicinal Chemistry Research, 21(10), 2920-2925. http://dx.doi.org/10.1007/s00044-011-9812-0

Divakar, S., \& Maheswaran, M. (1997). Structural studies on inclusion compounds of $\beta$-cyclodextrin with some substituted phenols. Journal of Inclusion Phenomena and Macrocyclic Chemistry, 27, 113-126. http://dx.doi.org/10.1023/A:1007949215051

Duan, M. S., Zhao, N., Ossurardóttir, I. B., Thorsteinsson, T., \& Loftsson, T. (2005). Cyclodextrin solubilization of the antibacterial agents triclosan and triclocarban: Formation of aggregates and higher-order complexes. International Journal of Pharmaceutics, 297(1/2), 213-222. http://dx.doi.org/10.1016/j.ijpharm.2005.04.007

Fang, Z., \& Bhandari, B. (2010). Encapsulation of polyphenols - A review. Trends in Food Science $\mathcal{E}$ Technology, 21(10), 510-523. http://dx.doi.org/10.1016/j.tifs.2010.08.003

Ficarra, R., Tommasini, S., Raneri, D., Calabrò, M., Di Bella, M., Rustichelli, C., et al. (2002). Study of flavonoids/ $\beta$-cyclodextrins inclusion complexes by NMR, FTIR, DSC, X-ray investigation. Journal of Pharmaceutical and Biomedical Analysis, 29(6), 1005-1014. http://dx.doi.org/10.1016/S0731-7085(02)00141-3

Folch-Cano, C., Guerrero, J., Speisky, H., Jullian, C., \& Olea-Azar, C. (2013). NMR and molecular fluorescence spectroscopic study of the structure and thermodynamic parameters of EGCG/ $\beta$-cyclodextrin inclusion complexes with potential antioxidant activity. Journal of Inclusion Phenomena and Macrocyclic Chemistry, http://dx.doi.org/10.1007/s10847-013-0297-y

Ghanghoria, R., Kesharwani, P., Agashe, H. B., \& Jain, N. K. (2012). Transdermal delivery of cyclodextrin-solubilized curcumin. Drug Delivery and Translational Research, 3(3), 272-285. http://dx.doi.org/10.1007/s13346-012-0114-y

Goldwasser, J. (2010). The grapefruit flavonoid naringenin as a hepatitis c virus therapy: Efficacy, mechanism and delivery. Technology. Massachusetts Institute of Technology

Górnas, P., Neunert, G., Baczyński, K., \& Polewski, K. (2009). Beta-cyclodextrin complexes with chlorogenic and caffeic acids from coffee brew: Spectroscopic, thermodynamic and molecular modelling study. Food Chemistry, 114(1), 190-196. http://dx.doi.org/10.1016/j.foodchem.2008.09.048

Gou, J., Zou, Y., \& Ahn, J. (2011). Enhancement of antioxidant and antimicrobial activities of Dianthus superbus, Polygonum aviculare, Sophora flavescens, and Lygodium japonicum by pressure-assisted water extraction. Food Science and Biotechnology, 20(1), 283-287. http://dx.doi.org/10.1007/s10068-0110040-7

Grazul, M., \& Budzisz, E. (2009). Biological activity of metal ions complexes of chromones, coumarins and flavones. Coordination Chemistry Reviews, 253(21/22), 2588-2598. http://dx.doi.org/10.1016/j.ccr.2009.06.015

Haidong, L., Fang, Y., Zhihong, T., \& Changle, R. (2011). Study on preparation of $\beta$-cyclodextrin encapsulation tea extract. International Journal of Biological Macromolecules, 49(4), 561-566. http://dx.doi.org/10.1016/j.ijbiomac.2011.06. 013

Haiyun, D., Jianbin, C., Shuang, Z. G., \& Jinhao, P. (2003). Preparation and spectral investigation on inclusion complex of $\beta$-cyclodextrin with rutin. Spectrochimica Acta Part A: Molecular and Biomolecular Spectroscopy, 59(14), 3421-3429. http://dx.doi.org/10.1016/S1386-1425(03)00176-8

Haslam, E., \& Cai, Y. (1994). Plant polyphenols (vegetable tannins): Gallic acid metabolism. Natural Product Reports, 11(1), 41-66. http://dx.doi.org/10.1039/np9941100041

Havsteen, B. H. (2002). The biochemistry and medical significance of the flavonoids. Pharmacology $\mathcal{E}$ Therapeutics, 96(2/3), 67-202. http://dx.doi.org/10.1016/S0163-7258(02)00298-X

Hedges, A. R. (1998). Industrial applications of cyclodextrins. Chemical Reviews, 98(5), 2035-2044. S0009-2665(97)00014-9.

Heim, K. E., Tagliaferro, A. R., \& Bobilya, D. J. (2002). Flavonoid antioxidants: Chemistry, metabolism and structure-activity relationships. The Journal of Nutritional Biochemistry, 13(10), 572-584. http://dx.doi.org/10.1016/S0955-2863(02)00208-5

Hirose, K. (2001). A practical guide for the determination of binding constants. Journal of Inclusion Phenomena and Macrocyclic, 193-209.

Hirose, K. (2007). Determination of binding constants. Analytical methods in Supramolecular Chemistry, 17-54

Jug, M., Bećirević-Laćan, M., \& Beæireviæ-laæan, M. (2008). Cyclodextrin-based pharmaceuticals. Radiation Medical Sciences, 499(32), 9-26.

Jullian, C., Brossard, V., Gonzalez, I., Alfaro, M., \& Olea-Azar, C. (2011). Cyclodextrins-kaempferol inclusion complexes: Spectroscopic and reactivity studies. Journal of Solution Chemistry, 40(4), 727-739. http://dx.doi.org/10.1007/s10953-011-9674-6

Jullian, C., Moyano, L., Yañez, C., \& Olea-Azar, C. (2007). Complexation of quercetin with three kinds of cyclodextrins: An antioxidant study. Spectrochimica Acta Part A: Molecular and Biomolecular Spectroscopy, 67(1), 230-234. http://dx.doi.org/10.1016/j.saa.2006.07.006

Kim, H., Choi, J., \& Jung, S. (2009). Inclusion complexes of modified cyclodextrins with some flavonols. Journal of Inclusion Phenomena and Macrocyclic Chemistry, 64(1/2), 43-47. http://dx.doi.org/10.1007/s10847-009-9534-9
Kim, H., Kim, H., \& Jung, S. (2008). Aqueous solubility enhancement of some flavones by complexation with cyclodextrins. Bulletin of the Korean Chemical Society, 29(3), 590-594. http://dx.doi.org/10.5012/bkcs.2008.29.3.590

Krishnaswamy, K., Orsat, V., \& Thangavel, K. (2012). Synthesis and characterization of nano-encapsulated catechin by molecular inclusion with beta-cyclodextrin. Journal of Food Engineering, 111(2), 255-264. http://dx.doi.org/10.1016/j.jfoodeng.2012.02.024

Kumpugdee-Vollrath, M. (2012). Solid state characterization of trans resveratrol complexes with different cyclodextrins. Journal of the Asian, 1(2), $125-136$.

Li, H., Xu, X., Liu, M., Sun, D., \& Li, L. (2010). Microcalorimetric and spectrographic studies on host-guest interactions of $\alpha-, \beta-, \quad(\gamma$ and $\mathrm{M} \beta$-cyclodextrin with resveratrol. Thermochimica Acta, 510(1/2), 168-172. http://dx.doi.org/10.1016/j.tca.2010.07.011

Li, X., Li, H., Liu, M., Li, G., Li, L., \& Sun, D. (2011). From guest to ligand - A study on the competing interactions of antitumor drug resveratrol with $\beta$ cyclodextrin and bovine serum albumin. Thermochimica Acta, 521(1/2), 74-79. http://dx.doi.org/10.1016/j.tca.2011.04.007

Lim, C., \& Koffas, M. A. G. (2010). Bioavailability and recent advances in the bioactivity of flavonoid and stilbene compounds. Current Organic Chemistry, 14(716) $1727-1751$

Liu, B., Li, W., Zhao, J., Liu, Y., Zhu, X., \& Liang, G. (2013). Physicochemical characterisation of the supramolecular structure of luteolin/cyclodextrin inclusion complex. Food Chemistry, 141(2), 900-906. http://dx.doi.org/10.1016/j.foodchem.2013.03.097

Liu, B., Zhao, J., Liu, Y., Zhu, X., \& Zeng, J. (2012). Physicochemical [corrected] properties of the inclusion complex of puerarin and glucosyl- $\beta$ cyclodextrin. Journal of Agricultural and Food Chemistry, 60(51), 12501-12507. http://dx.doi.org/10.1021/jf304447x

Loftsson, T., \& Duchêne, D. (2007). Cyclodextrins and their pharmaceutical applications. International Journal of Pharmaceutics, 329(1/2), 1-11. http://dx.doi.org/10.1016/j.ijpharm.2006.10.044

López-Tobar, E., Blanch, G. P., Ruiz del Castillo, M. L., \& Sanchez-Cortes, S. (2012). Encapsulation and isomerization of curcumin with cyclodextrins characterized by electronic and vibrational spectroscopy. Vibrational Spectroscopy, 62, 292-298. http://dx.doi.org/10.1016/j.vibspec.2012.06.008

Lu, Z., Chen, R., Fu, R., Xiong, J., \& Hu, Y. (2011). Cytotoxicity and inhibition of lipid peroxidation activity of resveratrol/cyclodextrin inclusion complexes. Journal of Inclusion Phenomena and Macrocyclic Chemistry, 73(1-4), 313-320. http://dx.doi.org/10.1007/s10847-011-0058-8

Lu, Z., Cheng, B., Hu, Y., Zhang, Y., \& Zou, G. (2009). Complexation of resveratrol with cyclodextrins: Solubility and antioxidant activity. Food Chemistry, 113(1), 17-20. http://dx.doi.org/10.1016/j.foodchem.2008.04.042

Lucas-Abellán, C., Fortea, I., López-Nicolás, J. M., \& Núñez-Delicado, E. (2007) Cyclodextrins as resveratrol carrier system. Food Chemistry, 104(1), 39-44 http://dx.doi.org/10.1016/j.foodchem.2006.10.068

Ma, S.-X., Chen, W., Yang, X.-D., Zhang, N., Wang, S.-J., Liu, L., et al. (2012) Alpinetin/hydroxypropyl- $\beta$-cyclodextrin host-guest system: preparation, characterization, inclusion mode, solubilization and stability. Journal of Pharmaceutical and Biomedical Analysis, 67/68, 193-200. http://dx.doi.org/10.1016/j.jpba.2012.04.038

Manach, C., Williamson, G., Morand, C., Scalbert, A., Remesy, C., \& Rémésy, C. (2005). Bioavailability and bioefficacy of polyphenols in humans. I. Review of 97 bioavailability studies. American Journal of Clinical Nutrition, 81(Suppl. 1), 230-242.

Manakker, F., Vermonden, T., Vans Nostrum, C. F., Hennink, W. E., \& van de Manakker, F. (2009). Cyclodextrin-based polymeric materials: Synthesis, properties, and pharmaceutical/biomedical applications. Biomacromolecules, 10(12), 3157-3174. http://dx.doi.org/10.1021/bm901065f

Marques, H. M. C. (2010). A review on cyclodextrin encapsulation of essential oils and volatiles. Flavour and Fragrance Journal, 25(5), 313-326. http://dx.doi.org/10.1002/ffj.2019

Matsuda, H., \& Arima, H. (1999). Cyclodextrins in transdermal and rectal delivery. Advanced Drug Delivery Reviews, 36(1), 81-99. http://dx.doi.org/10.1016/S0169-409X(98)00056-8

Mercader-Ros, M. T., Lucas-Abellán, C., Fortea, M. I., Gabaldón, J. A., \& Núñez-Delicado, E. (2010). Effect of HP- $\beta$-cyclodextrins complexation on the antioxidant activity of flavonols. Food Chemistry, 118(3), 769-773. http://dx.doi.org/10.1016/j.foodchem.2009.05.061

Mercader-Ros, M. T., Lucas-Abellán, C., Gabaldón, J. A., Fortea, M. I., Martínez-Cachá, A., \& Núñez-Delicado, E. (2010). Kaempferol complexation in cyclodextrins at basic pH. Journal of Agricultural and Food Chemistry, 58(8), 4675-4680. http://dx.doi.org/10.1021/jf904218j

Merkl, R., Hradkova, I., Filip, V., \& Smidrkal, J. (2010). Antimicrobial and antioxidant properties of phenolic acids alkyl esters. Czech Journal of Food Sciences, 28(4) 275-279.

Miyake, K., Arima, H., Hirayama, F., Yamamoto, M., Horikawa, T., Sumiyoshi, H., et al. (2000). Improvement of solubility and oral bioavailability of rutin by complexation with 2-hydroxypropyl-beta-cyclodextrin. Pharmaceutical Development and Technology, 5(3), 399-407. http://dx.doi.org/10.1081/PDT-100100556

Mohan, P. R. K., Sreelakshmi, G., Muraleedharan, C. V., \& Joseph, R. (2012). Water soluble complexes of curcumin with cyclodextrins: Characterization by FT-Raman spectroscopy. Vibrational Spectroscopy, 62, 77-84. http://dx.doi.org/10.1016/j.vibspec.2012.05.002

Monti, D., Tampucci, S., Chetoni, P., Burgalassi, S., Saino, V., Centini, M., et al. (2011) Permeation and distribution of ferulic acid and its $\alpha$-cyclodextrin complex from 
different formulations in hairless rat skin. AAPS PharmSciTech, 12(2), 514-520. http://dx.doi.org/10.1208/s12249-011-9609-y

Munin, A., \& Edwards-Lévy, F. (2011). Encapsulation of natural polyphenolic compounds: A review. Pharmaceutics, 3(4), 793-829. http://dx.doi.org/10.3390/pharmaceutics3040793

Nguyen, T. A., Liu, B., Zhao, J., Thomas, D. S., \& Hook, J. M. (2013). An investigation into the supramolecular structure, solubility, stability and antioxidant activity of rutin/cyclodextrin inclusion complex. Food Chemistry, 136(1), 186-192. http://dx.doi.org/10.1016/j.foodchem.2012.07.104

Nichols, J. a., \& Katiyar, S. K. (2010). Skin photoprotection by natural polyphenols: Anti-inflammatory, antioxidant and DNA repair mechanisms. Archives of Dermatological Research, 302(2), 71-83. http://dx.doi.org/10.1007/s00403-009-1001-3

Orhan, D. D., Ozçelik, B., Ozgen, S., \& Ergun, F. (2010). Antibacterial, antifungal, and antiviral activities of some flavonoids. Microbiological Research, 165(6), 496-504. http://dx.doi.org/10.1016/j.micres.2009.09.002

Ozçelik, B., Orhan, I., \& Toker, G. (2006). Antiviral and antimicrobial assessment of some selected flavonoids. Journal of Biosciences, 61(9/10), 632-638.

Patro, N. M., Sultana, A., Terao, K., Nakata, D., Jo, A., Urano, A., et al.(2013). Comparison and correlation of in vitro, in vivo and in silico evaluations of alpha, beta and gamma cyclodextrin complexes of curcumin. Journal of Inclusion Phenomena and Macrocyclic Chemistry, http://dx.doi.org/10.1007/s10847-013-0322-1

Proestos, C., Chorianopoulos, N., Nychas, G.-J. E., \& Komaitis, M. (2005). RP-HPLC analysis of the phenolic compounds of plant extracts. investigation of their antioxidant capacity and antimicrobial activity. Journal of Agricultural and Food Chemistry, 53(4), 1190-1195. http://dx.doi.org/10.1021/jf040083t

Rahman, S., Cao, S., Steadman, K. J., Wei, M., \& Parekh, H. S. (2012). Native and $\beta$-cyclodextrin-enclosed curcumin: entrapment within liposomes and their in vitro cytotoxicity in lung and colon cancer. Drug Delivery, 19(7), 346-353. http://dx.doi.org/10.3109/10717544.2012.721143

Răileanu, M., Todan, L., Voicescu, M., Ciuculescu, C., \& Maganu, M. (2013). A way for improving the stability of the essential oils in an environmental friendly formulation. Materials Science \& Engineering C: Materials for Biological Applications, 33(6), 3281-3288. http://dx.doi.org/10.1016/j.msec.2013.04.012

Rocks, N., Bekaert, S., Coia, I., Paulissen, G., Gueders, M., Evrard, B., et al. (2012). Curcumin-cyclodextrin complexes potentiate gemcitabine effects in an orthotopic mouse model of lung cancer. British Journal of Cancer, 107(7), 1083-1092. http://dx.doi.org/10.1038/bjc.2012.379

Sánchez-Maldonado, A. F., Schieber, A., \& Gänzle, M. G. (2011). Structure-function relationships of the antibacterial activity of phenolic acids and their metabolism by lactic acid bacteria. Journal of Applied Microbiology, 111(5), 1176-1184. http://dx.doi.org/10.1111/j. 1365-2672.2011.05141.x

Sapino, S., Carlotti, M. E., Caron, G., Ugazio, E., \& Cavalli, R. (2008). In silico design, photostability and biological properties of the complex resveratrol/hydroxypropyl$\beta$-cyclodextrin. Journal of Inclusion Phenomena and Macrocyclic Chemistry, 63(1/2), 171-180. http://dx.doi.org/10.1007/s10847-008-9504-7

Scalbert, A., Johnson, I. T., \& Saltmarsh, M. (2005). Polyphenols: Antioxidants and beyond. American Journal of Clinical Nutrition, 81, 215-217.

Schwingel, L., Fasolo, D., Holzschuh, M., Lula, I., Sinisterra, R., Koester, L., et al. (2008). Association of 3-O-methylquercetin with $\beta$-cyclodextrin: Complex preparation, characterization and ex vivo skin permeation studies. Journal of Inclusion Phenomena and Macrocyclic Chemistry, 62(1/2), 149-159. http://dx.doi.org/10.1007/s10847-008-9450-4

Shuang, S., Pan, J., Guo, S., Cai, M., \& Liu, C. (1997). Fluorescence study on the inclusion complexes of rutin with $\beta$-cyclodextrin, hydroxypropyl$\beta$-cyclodextrin and $\gamma$-cyclodextrin. Analytical Letters, 30(12), 2261-2270. http://dx.doi.org/10.1080/00032719708001737

Shulman, M., Cohen, M., Soto-Gutierrez, A., Yagi, H., Wang, H., \& Goldwasser, J. (2011). Enhancement of naringenin bioavailability by complexation with hydroxypropoyl- $\beta$-cyclodextrin. PloS one, 6(4), e18033. http://dx.doi.org/10.1371/journal.pone.0018033

Singh, M., Sharma, R., \& Banerjee, U. C. (2002). Biotechnological applications of cyclodextrins. Biotechnology Advances, 20(5/6), 341-359.

Soares, L. A., Leal, A. F. V. B., Fraceto, L. F., Maia, E. R., Resck, I. S., Kato, M. J., et al. (2009). Host-guest system of 4-nerolidylcatechol in 2hydroxypropyl- $\beta$-cyclodextrin: preparation, characterization and molecular modeling. Journal of Inclusion Phenomena and Macrocyclic Chemistry, 64(1/2), 23-35. http://dx.doi.org/10.1007/s10847-009-9532-y

Sri, K. V., Kondaiah, a., Ratna, J. V., \& Annapurna, A. (2007). Preparation and characterization of quercetin and rutin cyclodextrin inclusion complexes. Drug Development and Industrial Pharmacy, 33(3), 245-253. http://dx.doi.org/10.1080/03639040601150195
Stella, V. J., \& Rajewski, R. A. (1997). Cyclodextrins: Their future in drug formulation and delivery. Pharmaceutical Research, 14(5), 556-567. http://dx.doi.org/10.1023/A:1012136608249

Stražišar, M., Andrenšek, S., \& Šmidovnik, A. (2008). Effect of $\beta$-cyclodextrin on antioxidant activity of coumaric acids. Food Chemistry, 110(3), 636-642. http://dx.doi.org/10.1016/j.foodchem.2008.02.051

Szejtli, \& Jozsef. (2004). Past, present, and future of cyclodextrin research. ChemInform, 36(17), 1825-1845. http://dx.doi.org/10.1002/chin.200517261

Szejtli, \& József. (1998). Introduction and general overview of cyclodextrin chemistry. Chemical Reviews, 98(5), 1743-1754. http://dx.doi.org/10.1021/cr970022c

Szejtli, \& József. (2003). Cyclodextrins in the textile industry. Starch - Stärke, 55(5), 191-196. http://dx.doi.org/10.1002/star.200390050

Tang, B., Ma, L., Wang, H., \& Zhang, G. (2002). Study on the supramolecular interaction of curcumin and beta-cyclodextrin by spectrophotometry and its analytical application. Journal of Agricultural and Food Chemistry, 50(6), 1355-1361.

Tommasini, S., Calabrò, M. L., Stancanelli, R., Donato, P., Costa, C., \& Catania, S. (2005). The inclusion complexes of hesperetin and its 7-rhamnoglucoside with (2-hydroxypropyl)-beta-cyclodextrin. Journal of Pharmaceutical and Biomedical Analysis, 39(3/4), 572-580. http://dx.doi.org/10.1016/j.jpba.2005.05.009

Tomren, M. A., Másson, M., Loftsson, T., \& Tønnesen, H. H. (2007). Studies on curcumin and curcuminoids XXXI. Symmetric and asymmetric curcuminoids: Stability, activity and complexation with cyclodextrin. International Journal of Pharmaceutics, 338(1/2), 27-34. http://dx.doi.org/10.1016/j.ijpharm.2007.01.013

Tønnesen, H. H., Másson, M., \& Loftsson, T. (2002). Studies of curcumin and curcuminoids. XXVII. Cyclodextrin complexation: solubility, chemical and photochemical stability. International Journal of Pharmaceutics, 244(1/2), $127-135$.

Uekama, K., Hirayama, F., \& Irie, T. (1998). Cyclodextrin drug carrier systems. Chemical Reviews, 98(5), 2045-2076.

Valenta, C., \& Auner, B. G. (2004). The use of polymers for dermal and transdermal delivery. European Journal of Pharmaceutics and Biopharmaceutics, 58, 279-289. http://dx.doi.org/10.1016/j.ejpb.2004.02.017

Wang, J., Cao, Y., Sun, B., \& Wang, C. (2011). Characterisation of inclusion complex of trans-ferulic acid and hydroxypropyl- $\beta$-cyclodextrin. Food Chemistry, 124(3), 1069-1075. http://dx.doi.org/10.1016/j.foodchem.2010.07.080

Wang, Y., Qiao, X., Li, W., Zhou, Y., Jiao, Y., \& Yang, C. (2009). Study on the complexation of isoquercitrin with beta-cyclodextrin and its derivatives by spectroscopy. Analytica Chimica Acta, 650(1), 124-130. http://dx.doi.org/10.1016/j.aca.2009.05.038

Yang, L.-J., Chen, W., Ma, S.-X., Gao, Y.-T., Huang, R., Yan, S.-J., et al.(2011). Host-guest system of taxifolin and native cyclodextrin or its derivative: Preparation, characterization, inclusion mode, and solubilization. Carbohydrate Polymers, 85(3), 629-637. http://dx.doi.org/10.1016/j.carbpol.2011.03.029

Yang, L.-J., Ma, S.-X., Zhou, S.-Y., Chen, W., Yuan, M.-W., Yin, Y.-Q., et al. (2013). Preparation and characterization of inclusion complexes of naringenin with $\beta$-cyclodextrin or its derivative. Carbohydrate Polymers, 98(1), 861-869. http://dx.doi.org/10.1016/j.carbpol.2013.07.010

Yatsu, F. K. J., Koester, L. S., Lula, I., Passos, J. J., Sinisterra, R., \& Bassani, V. L. (2013). Multiple complexation of cyclodextrin with soy isoflavones present in an enriched fraction. Carbohydrate Polymers, 98(1), 726-735. http://dx.doi.org/10.1016/j.carbpol.2013.06.062

Yu, Z., Cui, M., Yan, C., Song, F., Liu, Z., \& Liu, S. (2007). Investigation of heptakis(2,6di-O-methyl)-beta-cyclodextrin inclusion complexes with flavonoid glycosides by electrospray ionization mass spectrometry. Rapid Communications in Mass Spectrometry: RCM, 21(5), 683-690. http://dx.doi.org/10.1002/rcm.2883

Zhang, M., Li, J., Zhang, L., \& Chao, J. (2009). Preparation and spectral investigation of inclusion complex of caffeic acid with hydroxypropyl-beta-cyclodextrin. Spectrochimica Acta. Part A: Molecular and Biomolecular Spectroscopy, 71(5), 1891-1895. http://dx.doi.org/10.1016/j.saa.2008.07.014

Zhang, Q. F., Nie, H.-C., Shangguang, X. C., Yin, Z. P., Zheng, G. D., \& Chen, J. G. (2013). Aqueous solubility and stability enhancement of astilbin through complexation with cyclodextrins. Journal of Agricultural and Food Chemistry, 61(1), 151-156. http://dx.doi.org/10.1021/jf304398v

Zhao, M., Wang, H., Yang, B., \& Tao, H. (2010). Identification of cyclodextrin inclusion complex of chlorogenic acid and its antimicrobial activity. Food Chemistry, 120(4), 1138-1142. http://dx.doi.org/10.1016/j.foodchem.2009.11.044

Zhou, Q., Wei, X., Dou, W., Chou, G., \& Wang, Z. (2013). Preparation and characterization of inclusion complexes formed between baicalein and cyclodextrins. Carbohydrate polymers, 95(2), 733-739. http://dx.doi.org/10.1016/j.carbpol.2013.02.038 